\title{
VULNERABILIDAD, PROPAGANDA TERRORISTA ONLINE Y RECLUTAMIENTO EN EL CONTEXTO DEL TERRORISMO INTERNACIONAL
}

\author{
Francesco Rossi ${ }^{1}$ \\ Investigador postdoctoral, Universidad de Luxemburgo \\ Miembro de MacroCrimes \\ (Centre for European Legal Studies on Macro Crime) \\ Analista de EU Law Live \\ Miembro de Start InSight (Strategic Analysts and Research Team)
}

Sumario: 1. Vulnerabilidad y radicalización. - 2. Heterogeneidad de perfiles de los individuos radicalizados. - 3. Propaganda fundamentalista online y prácticas de reclutamiento. - 3.1. Hibridación de la propaganda y del reclutamiento de terroristas con la escenografía y las técnicas de marketing occidentales y la hipocresía del fastuoso estilo de vida de los jerarcas del Estado Islámico en Mosul. - 3.2. Apuestas sobre el futuro del Estado Islámico: la revalorización instrumentalizada del papel de las mujeres y los menores en la sociedad fundamentalista. - 3.2.1. Las mujeres. - 3.2.2. Los menores. - 4. El incierto destino de las «familias del Estado Islámico». - 5. Perspectivas y obstáculos en la lucha contra la propaganda y el reclutamiento de terroristas.

Resumen: La captación de terroristas conocidos como «internacionales» o «yihadistas» y la propaganda online son cuestiones contemporáneas cruciales. El Estado Islámico ha desarrollado un aparato de propaganda

1 Este artículo se ha realizado en el marco del proyecto de $\mathrm{I}+\mathrm{D}+\mathrm{I}$ «La ejecución de las penas por delitos de terrorismo» (Rti2018-095375-b-100) financiado por el ministerio de Ciencia, Innovación y Universidades de España. Versión integrada, tanto en el texto como en las notas a pie de página, de los artículos La parabola di donne e minorenni nel "Califfato globale": vulnerabilità, illusioni e traumi nel percorso dall'adesione al "Jihadismo" totalitario al suo ripudio (en proceso de publicación en Rassegna Italiana Di Criminologia). Agradezco a Dolores Utrilla (Profesora Contratada Doctora, Universidad De Castilla-La Mancha) la revisión del texto y a Elena Maculan (Post-Doc Senior Research Fellow, Ramón Y Cajal Excellence Program, UNED) sus valiosos comentarios. 
organizado y eficaz a escala mundial. Fuera de sus territorios, se sirve de una red que llama a personas vulnerables a convertirse en combatientes terroristas extranjeros (foreign terrorist fighters) o en lobos solitarios (lone wolves). El presente estudio analiza los principales objetivos, medios y efectos de la propaganda online y del reclutamiento de terroristas, y concluye que es necesario un cambio del actual paradigma de prevención. El objetivo multicultural más amplio es restablecer la confianza mutua entre las personas marginadas y/o radicalizadas, la sociedad y el Estado.

Abstract: The so-called «international» or «jihadi» terrorist recruitment and online propaganda are paramount contemporary issues. The Islamic State built an organised and efficient propaganda apparatus at global level. Outside its territories, it relies upon a network calling on vulnerable individuals to turn into foreign terrorist fighters or lone wolves. This paper analyses the main targets, means and effects of terrorist propaganda and recruitment. In the concluding remarks, the author argues that a change of the current preventive paradigm is necessary. The broader goal is to restore mutual trust between marginalised and/or radicalised individuals, society, and the State.

Palabras clave: vulnerabilidad - radicalización - terrorismo internacional - propaganda online - adoctrinamiento - reclutamiento - prevención - desradicalización

Keywords: Vulnerability - radicalisation - international terrorism - online propaganda - indoctrination - recruitment - prevention - deradicalisation

\section{Vulnerabilidad y radicalización}

El fenómeno de la radicalización, que puede conducir al reclutamiento - es decir, a la inclusión de un sujeto en las filas de una agrupación terrorista a través de un punto de contacto, físico o virtual, entre células europeas y de otros continentes ${ }^{2}-\mathrm{y}$ a la realización de otras actividades terroristas (preparatorias, ejecutivas o violentas) ${ }^{3}$, prolifera en contextos en los que hay individuos y colectivos que comparten esencialmente una condición: la vulnerabilidad ${ }^{4}$. Debido a la amplitud y a la marcada mul-

2 L. VIDINo, Il jihadismo autoctono in Italia: nascita, sviluppo e dinamiche di radicalizzazione, Milano, 2014, passim.

3 Ex multis, M.a. Cano Paños, F.J. Castro Toledo, Un análisis de las fases del proceso de radicalización islamista y su interpretación por parte de los tribunales españoles a partir de los datos suministrados por sentencias judiciales, en Revista Electrónica de Ciencia Penal y Criminología, núm. 20-15, 2018, pp. 3 ss.

4 G. Travaini, E. Regondi, S. Camisasca, P. Caruso, I. Merzagora, I meccanismi di radicalizzazione: giudici e criminologi a confronto, en Rassegna Italiana di Criminologia, 
tidisciplinariedad del tema, este artículo no puede ofrecer un panorama exhaustivo de las concepciones de la vulnerabilidad elaboradas, sobre todo, por la doctrina filosófica y psicoanalítica ${ }^{5}$. Baste aquí con señalar que cada posible significado de este fenómeno presenta una serie de facetas específicas caracterizadas por el hecho de estar orientadas culturalmente. Así, «las necesidades y los requisitos que hacen que las personas sean vulnerables se perciben de manera diferente en las diversas tradiciones culturales» ${ }^{6}$.

A los efectos del presente estudio, el término "vulnerabilidad» se utiliza para aludir a la situación de fragilidad y marginación en el contexto de las relaciones sociales (laborales, afectivas, religiosas, políticas e ideológicas) e incluso, como se verá más adelante, de las condiciones económicas. La vulnerabilidad hace que la persona sea susceptible a la persuasión, que abre la puerta a una intensa participación del individuo en un contexto aplastante ${ }^{7}$. En el caso de los menores y, en particular, de los niños, se añaden otras dos formas de fragilidad: la relacionada con la edad y la resultante de los maltratos y los traumas subsiguientes ${ }^{8}$. A ello se añade, en el caso de la población migrante, la fragilidad provocada por la falta de acompañamiento ${ }^{9}$. La vulnerabilidad viene determinada por una pluralidad de factores concomitantes de distinta naturaleza - ideo-

núm. 4, 2017, pp. 297 ss.; K.Y.A. McKennA, J.A. BARGH, Coming out in the age of the internet: identity "demarginalization» through virtual group participation, en Journal of Personality and Social Psychology, Vol. 75, Iss. 3, 1998, pp. 681 ss.; Y. TsFati, G. WEIMANN, www.terrorism.com: Terror on the Internet, en Studies in Conflict and Terrorism, Vol. 25, Iss. 5, 2002, pp. 317 ss.; R. CRUPI, Al di là del diritto penale: exit strategy dalla radicalizzazione, en V. Militello, A. Spena (cur.), Mobilità, sicurezza e nuove frontiere tecnologiche, Torino, 2018, pp. 275 ss.; con especial referencia a la radicalización en la prisión, A. SiLKE, Risk assessment of terrorist and extremist prisoners, en A. Silke (cur.), Prisons, Terrorism and Extremism: Critical Issues in Management, Radicalisation and Reform, London-New York, 2014, passim. Entre las aportaciones más recientes, E. DiEU, L. TESTOURI, O. SorEL, Proposition d'une méthodologie d'évaluation de l'identité en voie de radicalisation, en Revue internationale de criminologie et de police technique et scientifique, vol. LXXII, núm. 4, 2019, pp. 458 ss.; R. BERMEJO, ¿Qué tienen en común las respuestas a la COVID-19 y al extremismo violento?, en The Conversation, 2 julio 2020, https://theconversation.com/quetienen-en-comun-las-respuestas-a-la-covid-19-y-al-extremismo-violento-141056.

5 Sobre el tema, M.G. Bernardini, B. Casalini, O. Giolo, L. Re (cur.), Vulnerabilità: etica, politica, diritto, Roma, 2018. Para un amplio análisis del concepto de vulnerabilidad en el ámbito de los disability studies, M.G. BERNARDINI, Disabilità, giustizia, diritto. Itinerari tra filosofia del diritto e Disability Studies, Torino, 2016, en particular pp. 134 ss.

6 Ivi, p. 138, nt. 118.

7 R. Borum, Psychology of Terrorism, Tampa, 2004, p. 24; L.S. MarTuccI, Laicità e diritti nei programmi di deradicalizzazione dal terrorismo religioso, en Dirittifondamentali. it, núm. 4, 2018, pp. 1 ss.; EAD., Radicalizzati jihadisti: profilazione e deradicalizzazione Constitution-compliant, ivi, núm. 8, 2019, pp. 1 ss.

8 A. Speckhard, M. Ellenberg, Jesse Morton: A Story of Trauma and Radicalization, en Homeland Security Today, 25 agosto 2020, https://www.hstoday.us/subject-matter-areas/ counterterrorism/jesse-morton-a-story-of-trauma-and-radicalization/.

9 E. CuKani, Soggetti vulnerabili e tutela dei diritti: il caso dei minori stranieri non accompagnati, en Consulta online, II, 2019, pp. 257 ss. 
lógica, política, social, cultural, económica -, de una intensidad tal que generan un gran desconcierto e incomodidad al sujeto que los padece ${ }^{10}$. Sobre esta condición se activa el proceso de radicalización hacia el fundamentalismo "yihadista» ${ }^{11}$, cuyos efectos pueden conducir, en casos extremos, a un estado de anulación del individuo ${ }^{12}$.

Ya el manual «Un curso para el arte del reclutamiento» ( $A$ Course in the Art of Recruiting»), difundido online por Al-Qaeda, ofrecía «indicaciones sobre cómo identificar al 'candidato' que tiende a ser más vulnerable» ${ }^{13}$. La vulnerabilidad, relacionada con múltiples factores incluso de naturaleza diferente de la religiosa ${ }^{14}$, es una condición que acompaña a los sujetos fundamentalistas desde el principio hasta el final del camino de la radicalización (y que, de hecho, se agrava considerablemente a medida que la participación en los ambientes terroristas se hace más intensa).

En particular, parece posible distinguir dos momentos en los que la vulnerabilidad adquiere importancia en la relación entre el individuo y el entorno terrorista (célula, organización intermedia o estructura central).

10 C. De Rosa, A. Fiorillo, Oltre la religione. Il reclutamento dei foreign fighter nello Stato Islamico (ISIS), en Rassegna Italiana di Criminologia, núm. 4, 2017, pp. 244 ss.

11 Los debates dentro y fuera del mundo islámico acerca del significado real y los límites semánticos del término «yihad». En una síntesis extrema, se ha indicado que utilizar adjetivos como «internacional» o «transnacional» (G.D. MiLleR, Blurred Lines: The New 'Domestic' Terrorism, en Perspectives on Terrorism, 13, 3, 2019, pp. 63 ss.; acerca de los diferentes significados de estos dos términos, C. DEL Prado Higuera, E. SÁnchez DE Rojas Díaz, Terrorismo islamista: El caso de Al Gama'a al Islamiyya, Valencia, 2018, pp. 56 ss.) en lugar de «yihadista», «islámico» o «islamista» resulta más adecuado (o al menos más neutrales) para identificar y evocar el terrorismo objeto de análisis sin caer en lecturas excesivamente simplistas o incluso erróneas: P. MAGGIOLINI, Dal jihad al jihadismo: militanza e lotta armata tra XX e XXI secolo, en A. Plebani (cur.), Jihad e terrorismo. Da AlQa'ida all'ISIS: storia di un nemico che cambia, Milano, 2016, pp. 45 ss.

12 Como sucede con otros aspectos del fenómeno terrorista, parte de la doctrina ha evidenciado que también la capacidad del entorno fundamentalista de anular psicológicamente al individuo está sujeta a la evolución a lo largo del tiempo. De hecho, mientras que durante la experiencia Qaedista el efecto de la anulación de la subjetividad se derivaba de la compartición total de la ideología fundamentalista (A. SPERINI, I modelli sistemici del jihadismo: aspetti evolutivi in chiave anti-sistema, en R. Razzante (cur.), Comprendere il terrorismo. Spunti interpretativi di analisi e metodologie di contrasto del fenomeno, Pisa, 2019, p. 88), en la actualidad tal efecto parece producirse esencialmente debido a la militarización aún más acentuada y la mayor brutalidad de la vida en el Estado Islámico.

13 R. RAzZANTE, Terrorismo: la complessità di un fenomeno strutturale, en R. Razzante (cur.), Comprendere il terrorismo. Spunti interpretativi di analisi e metodologie di contrasto del fenomeno, cit., p. 7.

14 F. Rossi, The Multifactorial Process of Radicalisation to «Jihadi» Fundamentalism, en Criminal Justice Network, 28 junio 2020, https://www.criminaljusticenetwork.eu/en/ post/the-multifactorial-process-of-radicalisation-to-jihadi-fundamentalism. 
En un primer momento, la vulnerabilidad subjetiva no ha alcanzado todavía su punto máximo, pero es el preludio del proceso de radicalización. Puede verse en el estado de aislamiento, alienación o en cualquier caso de fragilidad acentuada en el que se implantan las técnicas de persuasión utilizadas por los reclutadores (vulnerabilidad de entrada). Este primer momento de la relación - personal o, como se verá, incluso impersonal - entre el sujeto expuesto a la radicalización y los adoctrinadores/reclutadores no siempre supone la iniciativa selectiva de estos últimos. De hecho, parece que a menudo ocurre lo contrario: mediante una especie de "terrorismo de libre acceso», el proceso de reclutamiento "opera desde abajo hacia arriba, de personas que solicitan unirse a grupos organizados, y no desde arriba hacia abajo, de grupos organizados que llevan a cabo una actividad de reclutamiento selectiva y planificada ${ }^{15}$. Esta lógica de reclutamiento ascendente no es accidental: a diferencia de la práctica propia del momento en que Al Qaeda dominaba la escena terrorista, los reclutadores del Estado Islámico ${ }^{16}$ tienden a ignorar de manera oportunista la inmadurez ideológica de los nuevos candidatos para colmar sus filas de sujetos religiosamente rudimentarios, pero radicalizados y de gran fiabilidad. El Estado Islámico se organiza de manera predominantemente pragmática y empresarial, renunciando a la pureza ideológica para fortalecerse dentro y fuera de los territorios bajo su influencia y valiéndose de la adhesión y la contribución de sujetos disponibles, independientemente de su percepción histórica y religiosa de la yihad ${ }^{17}$.

En un segundo momento, la vulnerabilidad es un efecto, agudizado al extremo, del estilo de vida del individuo en la sociedad fundamentalista que sólo culmina una vez que la experiencia dentro de ella ha terminado. Esta segunda vertiente del fenómeno remite a la situación del individuo que regresa - sobre todo en el caso de las mujeres que escapan de una condición de verdadera esclavitud, a riesgo de su vida - a su propio entorno de origen, repudiando completamente lo que ha experimentado y sufriendo los traumas derivados de ello, o incluso estando todavía expuesto a la influencia de la red terrorista (vulnerabilidad de salida).

15 R. Guolo, L'ultima utopia. Gli jihadisti europei, Milano, 2015, p. 89.

16 En esta investigación se hará referencia varias veces al Estado Islámico como la principal organización terrorista - también en lo que respecta a la propaganda fundamentalista y al reclutamiento de nuevos milicianos - en el panorama mundial. Sin embargo, el Estado Islámico no es en absoluto el único grupo terrorista que opera en Oriente Medio: además de Al Qaeda «ha surgido toda una serie de realidades [...] que, si bien se refieren al trasfondo operativo y doctrinal de IS y AQ, han sabido distinguirse de ellos, dando vida a modelos híbridos caracterizados por una marcada atención a las relaciones con las comunidades locales y por una fuerte autonomía» (A. PLEBANI, Introduzione, en A. Plebani (cur.), Jihad e terrorismo. Da Al-Qa'ida all'ISIS: storia di un nemico che cambia, cit., p. XIII).

17 A. SPERINI, I modelli sistemici del jihadismo: aspetti evolutivi in chiave anti-sistema, cit., pp. 85-86. 


\section{Heterogeneidad de perfiles de los individuos radicalizados}

$\mathrm{Si}$, pese a sus diversas facetas, la vulnerabilidad constituye un punto fijo en el análisis de los supuestos de radicalización, dicho análisis se articula prioritariamente por referencia al perfil tipológico de los sujetos que terminan en la red del fundamentalismo y a las formas en que la radicalización se gesta y se manifiesta en la realidad externa.

En lo que concierne a los tipos de sujetos que se introducen en la red fundamentalista, parte de la doctrina ha subrayado la inexistencia de investigaciones psicológicas que revelen cualidades o trayectos unívocos hacia la radicalización ${ }^{18}$. Las redes fundamentalistas atraen con sorprendente éxito a sujetos de ambos sexos, de todas las edades y de diferentes orígenes (incluso a los que se han convertido): jóvenes, incluso menores, así como adultos de mediana edad no necesariamente aislados de su entorno familiar ${ }^{19}$.

Partiendo de esta heterogénea casuística, que dificulta la realización de abstracciones, un estudio sociológico y psicoanalítico ha trazado siete perfiles del sujeto radicalizado: «Cyber Mobs» (criminales cibernéticos), "Loners» (solitarios), «Fantasists» (visionarios), «Thrill Seekers» (sujetos que buscan la excitación), «Moral Crusaders» (cruzados moralistas), «Narcissists» (narcisistas) e «Identity Seekers» (sujetos en búsqueda de una identidad) ${ }^{20}$.

Otra investigación sociológica ha identificado tres tipos ideales ${ }^{21}$. Para los lúdicos, la guerra contra el enemigo infiel - en la que la muerte se contempla como una posibilidad, pero no como un objetivo esencial representa una verdadera razón vital que no conoce límites racionales ni estratégicos. Para los mártires, el martirio prevalece sobre la guerra y da

18 P. Giannetakis, Psicologia del terrorismo, en R. Razzante (cur.), Comprendere il terrorismo. Spunti interpretativi di analisi e metodologie di contrasto del fenomeno, cit., p. 29. Sobre la variedad de investigaciones psicológicas (psicocognitivas, neuropsicológicas y psiquiátricas, psicopatológicas, psicosociológicas, psicocriminológicas) sobre el tema de la radicalización, E. Dieu, L. Testouri, O. Sorel, Proposition d'une méthodologie d'évaluation de l'identité en voie de radicalisation, cit., pp. 458 ss.

19 Emblemático en este sentido es el llamado "caso Fátima», en el que toda una familia se ha visto involucrada en un proceso de radicalización hacia el fundamentalismo impulsado, en particular, por una de las hijas (Maria Giulia Sergio) y apoyado también por algunos individuos ajenos a la familia, algunos residentes en Italia y otros en distintos países. Reconstruye los hechos y analiza el proceso judicial correspondiente D. ALBANESE, Le motivazioni della Corte d'Assise di Milano sul "caso Fatima»: spunti di riflessione su terrorismo internazionale e organizzazione di trasferimenti ex art. 270-quater.1 c.p., en Diritto penale contemporaneo, 28 marzo 2017, https://archiviodpc.dirittopenaleuomo.org/ d/5302-le-motivazioni-della-corte-dassise-di-milano-sul-caso-fatima-spunti-di-riflessionesu-terrorismo-in.

20 I. AwAN, Cyber-Extremism: Isis and the Power of Social Media, en Society, Vol. 54, Iss. 2, 2017, p. 146.

21 R. Guolo, L'ultima utopia. Gli jihadisti europei, cit., pp. 23 e 29 ss. Este paso del A. menciona F. KHOSROKHAVAR, I nuovi martiri di Allah, Torino, 2003. 
un sentido religioso - absolutista y nihilista - a la existencia terrenal. Para los rectificadores, la guerra y el martirio subliman la vocación revolucionaria a la subversión de un orden político y social profundamente injusto.

Otras investigaciones han propuesto una clasificación cuatripartita - en orden descendente de jerarquía - entre «enterpreneurs» (los líderes de la red terrorista), "protéges» (los directores intermedios de empresas terroristas), "misfits» (dedicados a actividades operativas y no directivas) y «drifters» (el último eslabón de la cadena, compuesto por sujetos no siempre homogéneos en cuanto a motivaciones y funciones, cuya elección se deja totalmente en manos de la cúpula de la red terrorista) ${ }^{22}$.

Otra clasificación cuatripartita de las categorías de individuos radicalizados es la propuesta por Andrew Silke con especial referencia al aspecto penitenciario del fenómeno. Combinando las perspectivas criminológica y psicológica, el autor distingue entre extremistas radicalizados (un grupo más amplio y heterogéneo compuesto por verdaderos creyentes), afiliados, vulnerables y reclutados en prisión ${ }^{23}$. A diferencia de la mayoría de las aportaciones sobre el tema, la citada clasificación sostiene que la radicalización no es un requisito indefectible para la comisión de delitos de terrorismo. En particular, la categoría de los afiliados estaría compuesta, sobre todo, por sujetos (amigos, familiares, etc.) conniventes con individuos radicalizados, pero que se limitarían a prestarles apoyo de diversa índole y por razones distintas de la convicción ideológica ${ }^{24}$.

En la doctrina española ${ }^{25}$ la representación piramidal del proceso de radicalización ha encontrado amplia difusión. Tomada de las contribuciones de Clark McCauley ${ }^{26}$, dicha pirámide - dominada por una élite de terroristas en la cima y alimentada en la base por un mayor número de sujetos vulnerables en riesgo o en fase de radicalización - estaría compuesta por simpatizantes, seguidores, activistas, radicales y terroristas ${ }^{27}$. Los simpatizantes y seguidores sólo llevan a cabo actividades de adoctrinamiento y/o propaganda terrorista. Los activistas aportan un verdadero apoyo logístico material, que incluye, por ejemplo, las tareas de los facilitadores, reclutadores, organizadores de viajes y financiadores. Los

22 P. NESSER, Joining jihadi terrorist cells in Europe. Exploring motivational aspects of recruitment and radicalization, en $\mathrm{M}$. Ranstorp (cur.), Understanding violent radicalization: terrorist and jihadist movements in Europe, London-New York, 2009, pp. 91 ss.

23 A. SILKE, Risk assessment of terrorist and extremist prisoners, cit., passim.

24 Ibidem.

25 Víd. la reconstrucción propuesta por M.A. CANO Paños, F.J. Castro Toledo, Un análisis de las fases del proceso de radicalización islamista y su interpretación por parte de los tribunales españoles a partir de los datos suministrados por sentencias judiciales, cit., pp. 4-5.

26 C. McCauley, Jujitsu Politics: Terrorism and Response to Terrorism, en P.R. Kimmel, C.E. Stout (cur.), Collateral Damage: The Psychological Consequences of America's War on Terrorism, Westport, 2006, pp. 45 ss.

27 M. Moyano, H. TrujlLlo, Radicalización islamista y terrorismo. Claves psicosociales, Granada, 2013, pp. 12 ss. 
radicales y los terroristas completan el proceso de radicalización internalizando, en mayor grado, la violencia como un instrumento político sistemático (aunque, según esta clasificación, sólo los terroristas llevarían a cabo realmente actos violentos o, en cualquier caso, serían incluso más peligrosos que los radicales en términos de predictibilidad) ${ }^{28}$.

En la progresión desde la base hasta la cima de la pirámide, Miguel Ángel Cano Paños distingue cuatro fases del proceso «ascendente» de radicalización: aproximación y primeros contactos, pre-radicalización/ auto-identificación, aislamiento y adoctrinamiento, y yihadización ${ }^{29}$. La aproximación y los primeros contactos funcionarían de arriba abajo, con miembros (también expertos) de las células del Estado Islámico que identifican a los posibles candidatos y los sitúan en contextos de grupo (físicos o virtuales) cuyo objetivo es radicalizarlos, adoctrinarlos y finalmente reclutarlos a través de una contribución mutua de fortalecimiento de la identidad e ideológico ${ }^{30}$. La pre-radicalización/auto-identificación se inscribe en el mencionado contexto de vulnerabilidad multifactorial, que pretende remediarse persiguiendo el ideal híbrido político-religioso de la yihad violenta ${ }^{31}$. El aislamiento y el adoctrinamiento determinan la disociación del individuo del contexto de sus relaciones humanas anteriores y una recalificación ideológica paralela y más intensa, que traduce la yihad violenta como una obligación ineludible para todos los creyentes $^{32}$. Por fin, la yihadización sublima la autoconcepción del individuo como luchador sagrado y mártir a favor de la causa de sus hermanos musulmanes oprimidos contra la tiranía de Occidente y del resto de infieles colonialistas. En esta cuarta y última fase, el individuo recibiría entrenamiento o, cada vez con mayor frecuencia, se entrenaría autónomamente con el fin de ejercer la violencia terrorista ${ }^{33}$.

Tampoco parece posible trazar una secuencia lógica y unívoca de las formas en que la radicalización se gesta y posteriormente se manifiesta en la realidad externa ${ }^{34}$. Esquemáticamente, resulta posible esbozar tres tipos distintos de casos: i) aquellos en los que el paso de la mera vulnerabilidad individual a la plena adhesión al fundamentalismo y, eventualmen-

28 Ivi, pp. 14-15.

29 M.A. Cano Paños, F.J. Castro Toledo, Un análisis de las fases del proceso de radicalización islamista y su interpretación por parte de los tribunales españoles a partir de los datos suministrados por sentencias judiciales, cit., pp. 6 ss., donde se recogen otras teorías influyentes acerca de la radicalización y la trayectoria del terrorismo elaboradas por la doctrina española y de otros países.

30 Ivi, p. 6.

31 Ivi, pp. 6-7.

32 Ivi, p. 7.

33 Ivi, p. 8 .

34 A. SPERINI, I modelli sistemici del jihadismo: aspetti evolutivi in chiave anti-sistema, cit., p. 92; A. SPENA, "Io ho ragione; tu sei morto!»Su terrorismo e radicalizzazione, en Mobilità, sicurezza e nuove frontiere tecnologiche, cit., p. 253, sub nt. 10 e ulteriori riferimenti bibliografici ivi riportati. 
te, al reclutamiento y posterior adiestramiento de terroristas se divide en varias fases y a menudo se produce con una contribución significativa de otros sujetos (búsqueda de contactos y acercamiento a entornos e individuos radicalizados, adoctrinamiento, organización de viajes a territorios donde se establecen grupos terroristas etc.); ii) aquellos en los que dichas fases se comprimen, manifestándose en formas más esenciales, y la contribución de otros sujetos se atenúa o incluso desaparece (cuando, por ejemplo, la búsqueda y la consulta de material con contenido terrorista en la Internet tienen lugar espontáneamente) ${ }^{35}$; iii) aquellos en los que la radicalización parece producirse en forma de adhesión instantánea al fundamentalismo. Según parte de la doctrina, existen casos de radicalisation expresse, en los que la adhesión puede verse seguida de una acción igualmente repentina y, como tal, muy difícil de prevenir ${ }^{36}$.

La verificabilidad concreta de los casos sub iii) es controvertida. Según un sector de la doctrina, de hecho, todo acto terrorista (violento o preparatorio, rastreado por las autoridades o desconocido) representaría el resultado de un auténtico proceso ${ }^{37}$ que adoptaría al menos la forma mínima de una conversión potencialmente breve, pero no instantánea ${ }^{38}$.

En cualquier caso, es precisamente en los casos en que la radicalización se produce a través de un proceso articulado en varias fases y progresivamente orientado a la realización de actos terroristas violentos donde se pueden observar los síntomas típicos de la mencionada condición de vulnerabilidad de salida. Las prácticas inhumanas que el Estado Islámico ejerce y obliga a perpetrar tienen un impacto tan grave en el estado de salud del individuo que, en casos no infrecuentes, generan otra crisis de identidad, seguida de una «reestructuración del ego» ${ }^{39}$.

\section{Propaganda fundamentalista online y prácticas de reclutamiento}

La fortaleza del Estado Islámico y de sus grupos terroristas satélites depende no sólo de cuántos y cuáles son los territorios del Oriente Medio que permanecen bajo su dominio, ni de cuántos combatientes extranjeros pueden utilizar. De hecho, la diversidad de factores que subyacen a la radi-

35 M.A. Cano Paños, F.J. Castro Toledo, Un análisis de las fases del proceso de radicalización islamista y su interpretación por parte de los tribunales españoles a partir de los datos suministrados por sentencias judiciales, cit., pp. 12-13.

36 A. Garapon, M. Rosenfeld, Démocraties sous stress. Les défis du terrorisme global, París, 2016, p. 98. También, P. LEgRENZI, Reazioni al terrorismo. Vulnerabilità, paura, rischio e pericolo, en il Mulino, núm. 6, 2001, p. 1026.

37 Ibidem.

38 A. SPENA, «Io ho ragione; tu sei morto!» Su terrorismo e radicalizzazione, cit., p. 257.

39 R. Guolo, L'ultima utopia. Gli jihadisti europei, cit., p. 25. 
calización y al terrorismo internacional deslocaliza la expansión del Estado Islámico de la casa madre de Oriente Medio, ligándolo a actividades desmaterializadas con una dimensión transnacional: el adoctrinamiento dirigido a reclutar lobos solitarios y la «externalización de la violencia» ideológica ${ }^{40}$.

Tal adoctrinamiento puede tener lugar en un período de tiempo más o menos prolongado, en lugares diferentes, y conducir a la realización de actividades distintas. En este contexto, una de las dimensiones del fenómeno más relevantes es la de la propaganda fundamentalista en línea ${ }^{41}$.

El reclutamiento por parte del Estado Islámico comenzó oficialmente a partir del discurso pronunciado por el Califa Abu Bakr al-Baghdadi en la Gran Mezquita de al-Nuri en Mosul, en julio de 2014: «hacemos un llamamiento especial a los estudiosos, los expertos en jurisprudencia islámica, los periodistas, y especialmente a los jueces, a las personas con conocimientos militares, a los funcionarios, [...] a los médicos e ingenieros de todas las diferentes especialidades y sectores. Los llamamos y les recordamos que teman a Alá, ya que su traslado es una obligación individual, para que puedan responder a la desesperada necesidad que tienen los musulmanes de ellos» ${ }^{42}$. Cuatro años antes, Anwar Al Awlaki - ciudadano estadounidense, influyente exponente del fundamentalismo «islámico», adoctrinador y reclutador de terroristas asesinado en 2011 en ejecución de la lista de objetivos de Barack Obama - había grabado el vídeo «Llamada a la Yihad». En él se instigaba a la integración en las filas terroristas de las tierras islámicas o a la contribución a la causa mediante la violencia.

Entre quienes se han adherido a la convocatoria del Estado Islámico, muchos son expertos en nuevas tecnologías ${ }^{43}$, que se emplean para divulgar su misión ${ }^{44}$. Los reclutadores usan «técnicas precisas de marketing

40 S. DAmbruoso, Jihad. La risposta italiana al terrorismo: le sanzioni e le inchieste giudiziarie. Con storie di foreign fighters in Italia, Roma, 2018, p. 43.

41 Entre las aportaciones más recientes, S. Mendoza CALderón, Medidas contra la radicalización terrorista en la Unión Europea y su persecución penal en España, en A.I. Pérez Cepeda (dir.), M. Ruiz Arias (coord.), El terrorismo en la actualidad: un nuevo enfoque político criminal, Valencia, 2018, pp. 113 ss.

42 Al-Hayat Media Center 2014.

43 A.B. Atwan, Islamic State: The Digital Caliphate, Berkeley, 2015, p. 145.

44 Subrayan el papel de la estrategia de comunicación terrorista mediante el ejemplo emblemático de las grabaciones de vídeo durante la decapitación de los prisioneros capturados por el Estado Islámico R. Guolo, Jihad e "violenza sacra», en S. De Maglie, S. Seminara (cur.), Terrorismo internazionale e diritto penale, Padova, 2007, p. 25; G. TRAVAINI, E. Regond, S. CAmisasca, P. CARuso, I. Merzagora, I meccanismi di radicalizzazione: giudici e criminologi a confronto, cit., p. 298; F. FASANI, Terrorismo islamico e diritto penale, Milano, 2016, en particular p. 94; F. GALLI, The Law on terrorism: The UK, France and Italy compared, Bruselas, 2015, pp. 18-19; J.M. Perceval, El terror y el terrorismo. Cómo ha gestionado la humanidad sus miedos, Madrid, 2017, pp. 314 ss. 
político» ${ }^{45}$ y canales - en ocasiones muy sofisticados ${ }^{46}$, otras veces muy sencillos de utilizar - para transmitir materiales que en la mayoría de los casos contienen una verdadera «metodología del atentado» ${ }^{47}$. Las nuevas tecnologías han fomentado el desarrollo del «jihād electrónico» ${ }^{48}$, «"popular' y de libre acceso " ${ }^{49}$, que garantiza tanto a los afiliados al nivel central de la organización terrorista como a los lobos solitarios la disponibilidad de nuevos instrumentos eficaces y universales ${ }^{50}$ capaces de alimentar un "proceso de odio en línea ${ }^{51}$ a un coste muy bajo. Baste con mencionar el papel central que asumen las redes sociales, las aplicaciones de mensajería instantánea ${ }^{52}$ y las plataformas clouds; las revistas fundamentalistas online (especialmente Dabiq e Inspire), también disponibles en idiomas occidentales como el inglés, el francés y el alemán ${ }^{53}$, e incluso, según análisis más recientes, el chino y el tayiko ${ }^{54}$; los medios que ofrece el deep

45 R. Guolo, L'ultima utopia. Gli jihadisti europei, cit., p. 73.

46 A. Beutel, S.M. Weine, A. Saeed, A. Spahic Mihajlovic, A. Stone, J. OAKley Beahrs, S.B. ShanfiEld, Field Principles for Countering and Displacing Extremist Narratives, en Journal of Terrorism Research, Vol. 7, Iss. 3, 2016, p. 35.

47 S. AcAmPA, Applicazione delle tecniche di content analysis ai magazine di propaganda dello stato islamico: la chiamata alle armi di Rumiyah, en Rivista di Criminologia, Vittimologia e Sicurezza, Vol. XII, núm. 2, 2018, pp. 46 ss. Entre los materiales más difundidos se encuentra el manual "Da'wat al-muqawamah al-islamiyyah al-'alamiyyah» («Apelación a la resistencia islámica mundial»): R. Guolo, L'ultima utopia. Gli jihadisti europei, cit., p. 52.

48 M. FIOcca, Modernità ed effetti collaterali: il brodo di coltura del terrorismo islamico, en R. Wenin, G. Fornasari (cur.), Diritto penale e modernità. Le nuove sfide fra terrorismo, sviluppo tecnologico e garanzie fondamentali, Napoli, 2017, p. 223. De manera similar, describe el fenómeno de la "cyber jihad» y sus implicaciones I. AwAN, Cyber-Extremism: Isis and the Power of Social Media, cit., pp. 138 ss.

49 A. SPERINI, I modelli sistemici del jihadismo: aspetti evolutivi in chiave anti-sistema, cit., p. 86.

50 Ex multis, D. Denning, Terror's web: how the internet is transforming terrorism, en M. Yar, Y. Jewekes (cur.), Handbook of Internet Crime, Milton, 2010, pp. 194 ss.

51 I. AWAN, Cyber-Extremism: Isis and the Power of Social Media, cit., p. 139.

52 Sobre todo Telegram, Whatsapp y Signal, gracias a sus características de encriptación (A. Shehabat, T. Mitew, Black-boxing the Black Flag: Anonymous Sharing Platforms and ISIS Content Distribution Tactics, en Perspectives on Terrorism, Vol. 12, Iss. 1, 2018, p. 81; A. Shehabat, T. Mitew, Y. Alzoubi, Encrypted Jihad: Investigating the Role of Telegram App in Lone Wolf Attacks in the West, en Journal of Strategic Security, Vol. 10, núm. 3, 2017, pp. 27 ss.); pero la lista podría ser ampliada, por ejemplo, con SureSpot y Kik (A. MELEAGROUHitchens, S. Hughes, The Threat to the United States from the Islamic State's Virtual Entrepreneurs, en CTC Sentinel, vol. 10, núm. 3, Marzo 2017, https://ctc.usma.edu/thethreat-to-the-united-states-from-the-islamic-states-virtual-entrepreneurs/). En realidad, algunos datos estadísticos recopilados por una parte de la doctrina han mostrado una tendencia a utilizar principalmente - al menos hasta 2014 - los canales YouTube, Twitter e Facebook: I. AwAN, Cyber-Extremism: Isis and the Power of Social Media, cit., p. 139.

53 S. ACAMPA, Applicazione delle tecniche di content analysis ai magazine di propaganda dello stato islamico: la chiamata alle armi di Rumiyah, cit., pp. 48 ss.; R. Guolo, L'ultima utopia. Gli jihadisti europei, cit., pp. 84 ss.

54 M. SERAFINI, L'ombra del nemico. Una storia del terrorismo islamista, Milano, 2020, p. 42. 
$w_{e} b^{55} \mathrm{o}$ incluso los videojuegos para adolescentes vulnerables ${ }^{56}$. La atracción de los videojuegos había sido explotada por diversos grupos - desde Ezbollah hasta el Estado Islámico, pasando por Al Qaeda - para inculcar la cultura de la yihad violenta y «enseñar el alfabeto árabe de forma interactiva a los más jóvenes» ${ }^{57}$. Entre las estrategias más recientes, además, mediante «una clave cifrada y el cambio de algunos píxeles [...] se difunden en las redes sociales fotos que contienen mensajes que sólo los 'expertos' pueden descifrar y leer a través de ciertos códigos» ${ }^{58}$.

Ya sea garantizando el anonimato ${ }^{59} \mathrm{o}$ aportando visibilidad a quienes han abrazado con orgullo la causa fundamentalista ${ }^{60}$, Internet facilita en gran medida la reproducción de contenidos estratégicos para el proyecto terrorista ${ }^{61}$. Los materiales digitales son útiles para la coordinación de las células descentralizadas y los elementos superiores de la cadena fundamen-

55 L. Picotтi, Quale diritto penale nella dimensione globale del cyberspace?, en Diritto penale e modernità. Le nuove sfide fra terrorismo, sviluppo tecnologico e garanzie fondamentali, cit., pp. 309 ss.; R. FLoR, Cyber-terrorismo e diritto penale in Italia, ivi, pp. 325 ss.; I. SAlvadori, Il diritto penale dei software a duplice uso, ivi, pp. 361 ss.; C. LAMBERTI, Gli strumenti di contrasto al terrorismo e al cyber-terrorismo nel contesto europeo, en Rivista di Criminologia, Vittimologia e Sicurezza, Vol. VIII, núm. 2, 2014, pp. 142 ss.; S. Morán BLANCO, La ciberseguridad y el uso de las Tecnologias de la Información y la Comunicación (TIC) por el terrorismo, en Revista española de derecho internacional, núm. 2, 2017, pp. 195 ss.

56 En este sentido, A. CHRISTIEN, The Representation of Youth in the Islamic State's Propaganda Magazine Dabiq, en Journal of Terrorism Research, Vol. 7, Iss. 3, 2016, p. 1. A veces, los videojuegos de guerra más populares - uno en particular, Call of Duty - también se mencionan para acentuar el estado de exaltación que se experimenta en la guerra en Siria en nombre del Estado Islámico: S. LuCAS, Syria Interview: Islamic State of Iraq's Abu Sumayyah al-Britani on Conflict and the Caliphate, en EA Worldview, 11 Junio 2004, https://eaworldview.com/2014/06/syria-interview-islamic-state-of-iraq-abu-sumayyah-albritani-conflict-caliphate/.

57 V. Ciappina, Videogiochi e cyber jihad: dimensioni ed effetti, en \#ReaCT2020 Rapporto sul terrorismo e il radicalismo in Europa, 2020, p. 31.

58 G. Criscuolo, L'evoluzione della comunicazione dello stato islamico, ivi, p. 25.

59 G.M. TERUEL LOZANO, Internet, incitación al terrorismo y libertad de expresión en el marco europeo, en InDret, núm. 3, 2018, p. 22. Un estudio sobre el uso de otros portales menos populares como Sendvid.com, Justpaste.it, Dump.to, Share.it, Woodvid. com, Archive.org, WordPress, Pinterest y Tumblr para la distribución anónima de contenido terrorista online puede encontrarse en A. SHEHABAT, T. Mitew, Black-boxing the Black Flag: Anonymous Sharing Platforms and ISIS Content Distribution Tactics, cit., pp. 81 ss. La necesidad de garantizar el anonimato se hizo sentir especialmente tras las medidas de suspensión de las cuentas a través de las cuales se publicaba material de contenido terrorista. Estas medidas han sido aplicadas, por ejemplo, por YouTube y los principales social media. Las redes fundamentalistas se han reorganizado rápidamente utilizando diferentes canales, a veces sin condiciones de uso realmente restrictivas (ibidem).

60 La doble posibilidad de propagar la ideología fundamentalista utilizando Internet de forma anónima o revelando la propia identidad se ha analizado, en la doctrina, ya en relación con el «viejo ciclo» del terrorismo internacional: A.N. JoInson, Self-disclosure in computer-mediated communication: the role of self-awareness and visual anonimity, en European Journal of Social Psychology, núm. 31, 2000, pp. 177 ss.

61 S. ACAMPA, Applicazione delle tecniche di content analysis ai magazine di propaganda dello stato islamico: la chiamata alle armi di Rumiyah, cit., pp. 51-52. 
talista, así como para reforzar el mensaje difundido ${ }^{62}$. Además, la innovación tecnológica y comunicativa ha permitido a los terroristas desvincular parcialmente el proceso de radicalización de la existencia de relaciones cara a cara ${ }^{63}$.

También el modus operandi de los lobos solitarios ha cambiado: piénsese, por ejemplo, en los atentados realizados con armas blancas, precedidos por la difusión de varios dossieres de la revista fundamentalista Rumiyah. Éstos se centraban en «lo que los yihadistas llaman la Intifada de los cuchillos, es decir, el uso de armas blancas en sustitución de las armas de fuego o los explosivos ${ }^{64}$. Según algunos expertos, adoctrinar a los lobos solitarios de todo el mundo e inducirlos a llevar a cabo este tipo de ataques son hoy en día los principales objetivos de la propaganda terrorista online, más que el reclutamiento de combatientes extranjeros ${ }^{65}$. La radicalización y el terrorismo internacional supondrían el resultado de una cultura (o identidad) fundamentalista que «no ha sido destruida junto con el Estado Islámico, que sobrevive y que puede dar vida a otras sociedades similares ${ }^{66}$ : tanto es así que «existe la posibilidad de que exista un Estado Islámico incluso [...] en ausencia de su propia geografía de referencia ${ }^{67}$.

Un nuevo frente de propaganda que deberá ser examinado por la doctrina se refiere a la pandemia de Covid-19, descrita por el Estado Islámico como prueba divina de los pecados de los occidentales. En el futuro, la narrativa terrorista sobre esta cuestión podría no sólo servir como medio de reclutamiento, sino también incentivar un posible resurgimiento de la amenaza del terrorismo biológico. Además, las graves repercusiones económicas de la pandemia podrían afectar a la disponibi-

62 A. Shehabat, T. Mitew, Black-boxing the Black Flag: Anonymous Sharing Platforms and ISIS Content Distribution Tactics, cit., p. 84.

63 M. Fiocca, Modernità ed effetti collaterali: il brodo di coltura del terrorismo islamico, cit., p. 207.

64 S. ACAMPA, Applicazione delle tecniche di content analysis ai magazine di propaganda dello stato islamico: la chiamata alle armi di Rumiyah, cit., p. 68 (y, para el ejemplo ulterior de los «truck attacks», p. 69). Con respecto a las estrategias de planificación y ejecución de los atentados terroristas que se perpetraron en Europa de 1994 a 2013, cuando " [b] ombing [was] the dominant attack type», P. NESSER, A. STENERSEN, The Modus Operandi of Jihadi Terrorists in Europe, en Perspectives on Terrorism, Vol. 8, Iss. 6, diciembre 2014, en particular p. 7.

65 M. SERAFINI, L'ombra del nemico. Una storia del terrorismo islamista, cit., pp. 108-109.

66 A.M Cossiga, Terrorismo: uno sguardo antropologico, en R. Razzante (cur.), Comprendere il terrorismo. Spunti interpretativi di analisi e metodologie di contrasto del fenomeno, cit., p. 25.

67 A. Ricci, Geografia, globalizzazione e potere del terrorismo jihadista. L'autorappresentazione globale del califfato, ivi, p. 43. 
lidad de recursos para realizar programas de lucha contra la propaganda terrorista ${ }^{68}$ y actividades de repatriación de ex foreign fighters ${ }^{69}$.

\subsection{Hibridación de la propaganda y del reclutamiento de terroristas con la escenografía y las técnicas de marketing occidentales y la hipocresía del fastuoso estilo de vida de los jerarcas del Estado Islámico en Mosul}

Las actividades terroristas online explotan Internet como caja de resonancia para la propagación del terror a través de mensajes que amenazan la coexistencia pacífica de las sociedades ${ }^{70}$ y ofrecen a los musulmanes perdidos una "patria portátil'» que «les hace existir desde el punto de vista social» ${ }^{71}$. Por ejemplo, estos sujetos reivindican los ataques cometidos en cualquier punto del planeta o instigan nuevos ataques aprovechando también el impacto generado por la violencia y las técnicas y efectos cinematográficos especiales. El Estado Islámico cultiva la «estética del terror» ${ }^{72}$ e inmortaliza imágenes sugestivas para los destinatarios de la campaña de proselitismo. Incluso el ámbito del cine occidental de masas está siendo explotado para conferir mayor atracción a los mensajes fundamentalistas. En la búsqueda de énfasis, "[los] videos de los reclutadores están 'llenos de extractos de Star Wars, de Matrix o de El señor de los anillos, los mitos de los tiempos modernos'» ${ }^{73}$, con la finalidad de estimular la imaginación de gran parte de la población del planeta.

68 R. PANTuccI, Key Questions for Counter-Terrorism Post COVID-19, en RSIS, https:// raffaellopantucci.com/2020/04/24/key-questions-for-counter-terrorism-post-covid-19/, 24 abril 2020; Consejo de Seguridad de Naciones Unidas, Undécimo informe del Secretario General sobre la amenaza que plantea el EIIL (Daesh) para la paz y la seguridad internacionales y la gama de actividades que realizan las Naciones Unidas en apoyo de los Estados Miembros para combatir la amenaza, S/2020/774, 4 agosto 2020, pp. 8 ss.

69 Ivi, p. 10.

70 Sobre el tema, V. NARDI, La punibilità dell'istigazione nel contrasto al terrorismo internazionale. Il difficile bilanciamento tra esigenze di sicurezza e libertà di espressione, en Diritto penale contemporaneo - Rivista trimestrale, núm. 1, 2017, pp. 115 ss.; M.A. CANO PAÑos, Odio e incitación a la violencia en el contexto del terrorismo islamista. Internet como elemento ambiental, en Revista para el Análisis del Derecho, núm. 4, 2016, http://www. indret.com/pdf/1248.pdf; Z. BAuman, Paura liquida, Bari, 2010, en particular p. 133.

71 A. BASTEnier, Lo spirito del terrorismo, trad. por L. Tirocchi, Roma, 2019, p. 24.

72 A. SPERINI, I modelli sistemici del jihadismo: aspetti evolutivi in chiave anti-sistema, cit., p. 85. En el mismo sentido, con referencia no sólo al terrorismo fundamentalista, sino también al establecimiento del centro de Guantánamo, M. BARBERIS, Non c'è sicurezza senza libertà. Il fallimento delle politiche antiterrorismo, Bologna, 2017, p. 59.

73 A. Garapon, M. Rosenfeld, Démocraties sous stress. Les défis du terrorisme global, cit., pp. 97-98. 
Esta dimensión mediática ${ }^{74}$, que combina de forma oportunista la tradición y la modernidad, constituye uno de los elementos esenciales del fenómeno objeto de análisis: «sin comunicación el terrorismo no tendría sentido, sería un acto de violencia gratuita, una venganza sin eco» ${ }^{75}$. No es una coincidencia, de hecho, que del "potencial comunicativo y difusivo ${ }^{76}$ del mensaje fundamentalista en línea haya surgido la reacción descrita como «demonización de la red» ${ }^{77}$. Tal reacción ha sido incluida en el proceso de reforma de las normativas antiterroristas iniciado en los países europeos y extracomunitarios ${ }^{78}$. En esencia, en el marco de la lucha contra la difusión de la propaganda fundamentalista online los países occidentales están tratando de imponer un mayor control sobre la red a través de programas de vigilancia e intervención (en forma, por ejemplo, de eliminación de materiales cargados o cierre de cuentas) ${ }^{79}$. A fin de proteger a la red y a los usuarios de la difusión de contenido terrorista online, la Comisión Europea ha presentado la propuesta de Reglamento COM(2018)640 final, que incluye obligaciones de diligencia, reporte y evaluación de los reportes recibidos, remoción, vigilancia, y conservación por parte de los proveedores de servicios de hosting ${ }^{80}$.

La importación desde Occidente no se limita al plan de comunicación estratégica y a las técnicas de promoción. En Oriente Medio, donde en las zonas de guerra la pobreza de las poblaciones autóctonas es particularmente intensa y generalizada, las prácticas de reclutamiento también aprovechan incentivos de carácter puramente económico y material para inducir a los milicianos y operadores especializados a afiliarse al Estado Islámico. Las declaraciones de un ex foreign fighter recogidas en Siria muestran que los lugartenientes del Estado Islámico proporcionaron a los reclutas bienesde las grandes marcas del mercado globalizado - iPhone,

74 S. ACAMPA, Applicazione delle tecniche di content analysis ai magazine di propaganda dello stato islamico: la chiamata alle armi di Rumiyah, cit., p. 47. En el mismo sentido, W. Mwenda KaILemia, The Spectacle of Terrorism: Exploring the Impact of 'Blind Acting Out' and 'Phatic Communication', en Journal of Terrorism Research, Vol. 7, Iss. 2, 2016, p. 98.

75 L. Rigoni, Come $i$ media comunicano il terrorismo. Il jihad come format televisivo, en Comprendere il terrorismo. Spunti interpretativi di analisi e metodologie di contrasto del fenomeno, cit., p. 53.

76 R. FLOR, Cyber-terrorismo e diritto penale in Italia, cit., p. 355.

77 Ivi, p. 354.

78 Entre estos últimos, en particular, Estados Unidos ha introducido medidas para eliminar el contenido online, suspender las cuentas y llevar a cabo operaciones de piratería informática contra las páginas web para proteger la red y combatir la difusión de contenido terrorista: A. SHeHABAT, T. Mitew, Black-boxing the Black Flag: Anonymous Sharing Platforms and ISIS Content Distribution Tactics, cit., p. 81.

79 R. Guolo, L'ultima utopia. Gli jihadisti europei, cit., p. 77.

80 Sobre el tema, R. Pezzuto, Contenuti terroristici on line: l'Unione europea lavora a nuove norme per prevenirne la diffusione, en Diritto penale contemporaneo, 5 abril 2019. 
Samsung, Calvin Klein, Caterpillar - como parte de la remuneración por la afiliación y los servicios prestados ${ }^{81}$.

El Estado Islámico ha explotado la efímera atracción del lujo tanto en público como en privado, en abierta contradicción con los dogmas y valores paternalistas e intransigentes propagados por la corriente de la yihad violenta ${ }^{82}$. Antes de la operación de liberación de Mosul, los más altos rangos del Estado Islámico utilizaban el «Nineveh Hotel» (de cinco estrellas, reestructurado a propósito y renombrado como «Waritheen», «de los Herederos de Mahoma»). Por un lado, algunos vídeos difundidos por el Estado Islámico hacen alarde de la riqueza de que dispone y promueven la fastuosidad a la que pueden aspirar los nuevos reclutas. Por otro lado, en el hotel en cuestión se producían sistemáticamente situaciones de violencia contra las mujeres y actividades de ocio - como el consumo de cigarrillos y alcohol - consideradas inmorales por los milicianos para quienes la radicalización y el reclutamiento representan el camino de la redención divina de los pecados de su pasado ${ }^{83}$; así como prohibidas a los súbditos en estado de pobreza y hasta sancionadas con castigos corporales en caso de transgresión ${ }^{84}$.

\subsection{Apuestas sobre el futuro del Estado Islámico: la revalorización instrumentalizada del papel de las mujeres y los niños en la sociedad fundamentalista}

Aproximadamente a partir de 2017, el llamamiento a unirse a la causa del Estado Islámico se extendió no sólo a las mujeres adultas, sino también a los menores de ambos sexos. Con la finalidad de emanciparlos de lo que se describe como la colonización de los valores de Occidente ${ }^{85}$, la propaganda terrorista ofrece a estos sujetos un rol diferente y más relevante que en el pasado, aprovechando su eventual vulnerabilidad, menor madurez y aspiraciones de «rebelión, pertenencia, camaradería

81 A. Migotto, S. Miretti, Non aspettarmi vivo. La banalità dell'orrore nelle voci dei ragazzi jihadisti, Torino, 2017, p. 32.

82 S. Dambruoso, Jihad. La risposta italiana al terrorismo: le sanzioni e le inchieste giudiziarie. Con storie di foreign fighters in Italia, cit., p. 78.

83 L. VIDINo, Jihadisti europei in Siria. Profili, dinamiche di viaggio e risposte governative, en A. Plebani (cur.), Jihad e terrorismo. Da Al-Qa'ida all'ISIS: storia di un nemico che cambia, cit., pp. 63 ss.

84 M. RomAnELLI, Brevi note sulla prevenzione della radicalizzazione jihadista, en Sistema Penale, 20 marzo 2020, p. 3.

85 A. CHRISTIEN, The Representation of Youth in the Islamic State's Propaganda Magazine Dabiq, cit., p. 3. 
y aventura» ${ }^{86}$ para fidelizarlos al proyecto político-militar del Estado Islámico ${ }^{87}$.

La renovada participación de mujeres y niños en el terrorismo fundamentalista es un fenómeno que crece de manera alarmante ${ }^{88}$. Por citar solo algunos ejemplos, recientemente se han descubierto en Francia y en el Reino Unido algunas células fundamentalistas compuestas en su totalidad $-\mathrm{o}$ en una parte considerable - por mujeres ${ }^{89}$. Además, aunque hasta la fecha no existen investigaciones exhaustivas ni datos estadísticos suficientes para valorar el fenómeno en su totalidad ${ }^{90}$, algunos análisis recientes de las instituciones europeas señalan el uso de niños y adolescentes en vídeos y otros materiales de propaganda difundidos por el Estado Islámico; su prematuro adoctrinamiento en el fundamentalismo; su entrenamiento militar en campos especialmente diseñados al efecto; e incluso, en algunos casos, su participación en las ejecuciones de prisioneros capturados por los «soldados de Alá».

En Austria se ha observado que un número relevante de mujeres (incluidas menores de edad) se han marchado o tenían la intención de marcharse a zonas de guerra, o quieren regresar a su país de residencia o de procedencia ${ }^{91}$. Este fenómeno se ha observado también, por ejemplo, en Holanda, Bélgica y el Reino Unido. En Holanda se han registrado un total de más de 40 niños de entre 0 y 12 años) que viajaron a Siria o Irak con sus padres ${ }^{92}$. En Bélgica se ha señalado que las mujeres y los niños que regresan a sus hogares son motivo de preocupación y que la propaganda del Estado Islámico utiliza de manera recurrente escenas de entrenamiento de menores ${ }^{93}$. En el Reino Unido se ha puesto de relieve la significativa reducción de la edad media de los sujetos reclutados por

\footnotetext{
86 L. VIDINo, Il jihadismo autoctono in Italia: nascita, sviluppo e dinamiche di radicalizzazione, cit., p. 101.

87 O. CAHN, Quel accueil pour les djihadistes de retour en France? Les mesures et les qualifications envisageables, en Revue pénitentiaire et de droit penal, núm. 1, 2018, p. 18. Sobre la nueva estrategia del Estado Islámico para la participación de mujeres, F. BURIL, Changing God's Expectations and Women's Consequent Behaviors - How ISIS Manipulates "Divine Commandments» to Influence Women's Role in Jihad, en Contemporary Voices, Vol. 8, Iss. 3, 2017, pp. 1 ss.

88 Ivi, passim; L. vAN DER HeIDE, J. GEENEN, Children of the Calipate: Young IS Returnees and the Reintegration Challenge, en Security and Global Affairs, Special Issue "Jihadists in Syria and Iraq: Recalibrating Concepts, Threat Radar, and Reintegration Policies», Septiembre 2017, https://www.universiteitleiden.nl/en/news/2017/09/sga-special-issue, pp. 42 ss.

89 H. van Miert, The Right Target in Sight? Returnees and the Current Jihadist Threat, $i v i$, p. 40 .

90 L. van der Heide, J. Geenen, Children of the Calipate: Young IS Returnees and the Reintegration Challenge, cit., p. 51.

91 European Union Terrorism Situation and Trend Report, TE-SAT 2018, p. 28.

92 European Union Terrorism Situation and Trend Report, TE-SAT 2017, p. 13. En la doctrina, H. van Miert, The Right Target in Sight? Returnees and the Current Jihadist Threat, cit., p. 32 .

93 TE-SAT 2017, cit., p. 13.
} 
las fuerzas armadas terroristas ${ }^{94}$ - donde el individuo radicalizado más joven incluido en los datos estadísticos tenía quince años ${ }^{95}$ - y el aumento del número de menores involucrados en ellas. Como señala el TE-SAT 2020 («European Union Terrorism Situation and Trend Report»), la misma tendencia se observa en España, donde las autoridades nacionales han perseguido redes dedicadas al adoctrinamiento, el reclutamiento y la organización del traslado de jóvenes, incluidos menores, a los territorios del Estado Islámico. Además, el 24 de noviembre de 2020, una mujer suiza de 28 años de edad, al parecer ya conocida por las autoridades, atacó a dos personas gritando su pertenencia al Estado islámico.

Asimismo, los medios de comunicación dan cuenta de episodios en los que han participado menores o en los que estos últimos han aparecido muy expuestos a los peligros de la radicalización, o en los que han pasado a la acción violenta impulsados por el hetero- o el auto- adoctrinamiento al fundamentalismo. En Italia se han producido varios casos de este tipo. En Trieste, la policía intervino contra un joven de 15 años dedicado a la propaganda terrorista en un canal activado a través de la aplicación de mensajería Telegram ${ }^{96}$. En Foggia, un ciudadano italiano de origen egipcio fue arrestado por impartir lecciones instigando al terrorismo en el centro islámico "Al Dawa» a miembros de un grupo de unos quince niños de entre 4 y 10 años ${ }^{97}$. En un centro de acogida de menores en Florencia, una investigación reciente sobre seis jóvenes - algunos de ellos menores - ha recogido indicios de supuestas actividades de auto- $\mathrm{y}$ de hetero-adoctrinamiento al fundamentalismo ${ }^{98}$. En Francia, en enero de 2016, un joven de origen kurdo - de diecisiete años en el momento de su condena, y sólo quince cuando cometió el delito - fue condenado por el Tribunal Penal de Menores a siete años de prisión por intento de homicidio con finalidad de terrorismo, por haber herido a un profesor judío con un machete en nombre de la ideología fundamentalista ${ }^{99}$.

El fenómeno se ha observado también en Alemania. En enero de 2017, una ciudadana de 16 años de origen marroquí fue condenada a

94 Ibidem.

95 S. Mullins, 'Home-Grown' Jihad. Understanding Islamist Terrorism in the US and UK, London, 2016, p. 145.

96 M. SERAFInI, Trieste, il jihadista di 15 anni e il team di pedagogisti che prova a rieducarlo, en Corriere della sera, 7 Abril 2018, https://www.google.it/amp/www.corriere. it/esteri/18_aprile_07/minorenne-faceva-propaganda-isis-telegram-sara-deradicalizzato0eb0369a-3a24-11e8-a94c-7c30e3109c4d_amp.html.

97 Foggia, in arresto un egiziano: è accusato di far parte dell'Isis, en Corriere della sera, 27 Marzo 2018, https://www.google.it/amp/www.corriere.it/cronache/18_marzo_27/foggiaarresto-egiziano-accusato-far-parte-dell-isis-685c83a6-3182-11e8-a935-2154f7b1bc02_ amp.html.

98 A. Mollica, Firenze, sospetti terroristi nel centro minori, en Corriere della sera, 11 Mayo 2018, https://corrierefiorentino.corriere.it/firenze/notizie/cronaca/18_maggio_11/ firenze-sospetti-terroristi-centro-minori-9cc2ebac-54e7-11e8-998a-93ce1f8468 24 .shtml.

99 Eurojust, Terrorism Convictions Monitor 2017, pp. 9-10. 
seis años de prisión por herir gravemente a un agente de policía después de reunirse con miembros del Estado Islámico en Turquía, con la intención de llegar a Siria y después de regresar al país con su madre ${ }^{100}$. Asimismo, dos jóvenes de 17 años fueron condenados a penas de prisión por haber iniciado la ejecución de un ataque terrorista con un artefacto explosivo de fabricación propia en un lugar dedicado a la religión Sikh. Un tercer joven de la misma edad fue asimismo condenado a pena de prisión por haber aceptado llevar a cabo el ataque, aunque no participó en la ejecución ${ }^{101}$. En abril de 2017, un inmigrante sirio de 16 años fue condenado a dos años de prisión por planear un ataque terrorista con un artefacto explosivo improvisado. Aunque el ataque fue abortado debido a la intervención de las autoridades en una fase puramente preparatoria, el Tribunal competente consideró que existían pruebas suficientes tanto de la voluntad del menor de pasar a la acción como de la recepción de instrucciones sobre la fabricación del dispositivo de una persona perteneciente al Estado Islámico ${ }^{102}$.

Más allá de Europa y del Estado Islámico, el grupo terrorista Boko Haram «dirigió más de 434 atentados suicidas desde el 11 de abril de 2011 hasta el verano de 2017, de los cuales 244 fueron perpetrados por mujeres y 84 por menores» ${ }^{103}$. En los apartados siguientes se abordan con mayor detalle las características más significativas de la participación de las mujeres y los niños - autores y víctimas vulnerables, en diversos grados y no necesariamente en ese orden, del sistema del Estado Islámico - en las actividades terroristas.

Las mujeres

Se ha observado la adhesión de mujeres de todas las edades al modelo de Califato global implementado en el Estado Islámico y promovido por la propaganda terrorista ${ }^{104}$. Esta última representa al yihadismo violento como la única vía de emancipación auténtica de las mujeres musulmanas oprimidas, víctimas pasivas de ideologías dominadas por los hombres ${ }^{105}$. Además, la narrativa terrorista describe la radicalización y la lealtad al régimen del Estado Islámico como una opción de vida estilosa y atractiva, a través del uso de «símbolos, héroes, mártires» y «basando

100 Ivi, p. 10.

101 Ivi, p. 11.

102 Ibidem.

103 G. Olimpio, Terrorismi. Atlante mondiale del terrore, Milano, 2018, p. 21.

104 J. DAVIS, Women in Modern Terrorism: From Liberation Wars to Global Jihad and the Islamic State, Maryland, 2017.

105 S.J. JACOBSEN, Calling on Women: Female-Specific Motivation Narratives in Danish Online Jihad Propaganda, en Perspectives on Terrorism, 13, 4, 2019, pp. 14 ss. 
su credibilidad en la acción» ${ }^{106}$. En particular, las mujeres jóvenes son atraídas mediante campañas mediáticas centradas en la idolatría ficticia a hombres atractivos dedicados a la guerra santa, cuyas imágenes circulan por Twitter y otros canales, incluso el más popular Instagram ${ }^{107}$. Además, la propaganda «externalizada» - no referible a las plataformas oficiales del Estado Islámico - de algunas influencers del Estado fundamentalista «yihadista» sugestiona al público femenino mediante la publicación de imágenes que representan bienes comúnmente asociados con estados de bienestar material (como los automóviles) ${ }^{108}$.

Estas campañas combinan el impacto del contenido terrorista del mensaje con las técnicas de marketing establecidas en las sociedades occidentales. Además del prestigio de la adhesión a la yihad violenta, parte de las mujeres que se incorporan al Estado Islámico también están motivadas - a veces, predominantemente - por lazos familiares o emocionales. Un estudio reciente sobre la movilización terrorista de las mujeres del Cáucaso ha constatado que, junto con otros factores conducentes a procesos de radicalización, la presencia en Siria e Iraq de sus maridos $\mathrm{u}$ otros miembros de sus familias ha desempeñado un papel decisivo ${ }^{109}$.

Sin embargo, una vez incorporadas al Estado Islámico, las mujeres ven frustradas sus expectativas de emancipación, pues son esclavizadas y explotadas como máquinas reproductivas, viéndose incluso impedidas para utilizar métodos anticonceptivos. A excepción de los casos en que poseen conocimientos especializados útiles para el Estado Islámico, sus funciones consisten en realizar labores domésticas. Esta dinámica parece conocer de tres excepciones, a saber, el reclutamiento, las represalias contra las mujeres «infieles» y «traidoras», y la participación militar esporádica y desorganizada. Las mujeres muestran un interés creciente en dirigir canales de propaganda y adoctrinamiento, ocultando su género para evitar las tradiciones discriminatorias que les impedirían disfrutar

106 P. MAGgiolini, Dal jihad al jihadismo: militanza e lotta armata tra XX e XXI secolo, cit., p. 44.

107 A. Speckhard, M. Ellenberg, ISIS and the Militant Jihad on Instagram, en Homeland Security Today, https://www.hstoday.us/subject-matter-areas/cybersecurity/isisand-the-militant-jihad-on-instagram/, 21 julio 2020; A. BEutel, S.M. WeINE, A. SAEED, A. Spahic Minajlovic, A. Stone, J. Oakley Beahrs, S.B. Shanfield, Field Principles for Countering and Displacing Extremist Narratives, cit., p. 37; S. GHAJAR-KHOSRAVI, P. KWANTES, N. Derbentseva, L. Huey, Quantifying Salient Concepts Discussed in Social Media Content: An Analysis of Tweets Posted by ISIS Fangirls, en Journal of Terrorism Research, Vol. 7, Iss. 2, 2016, en particular p. 81; R. Guolo, L'ultima utopia. Gli jihadisti europei, cit., p. 41.

108 M. CRIEZIS, Online Deceptions: Renegotiating Gender Boundaries on ISIS Telegram, en Perspectives on Terrorism, 14, 1, 2020, p. 68.

109 A. KvaKhadze, Women from the Caucasus in the Syrian Conflict, en Perspectives on Terrorism, 14, 2, 2020, p. 72. También, D. Milton, B. Dodwell, Jihadi Brides? Examining a Female Guesthouse Registry from the Islamic State's Caliphate, en CTC Sentinel, 11, 5, 2018, pp. 16 ss. 
de las prerrogativas yihadistas de los hombres ${ }^{110}$, e incluso realizan atentados suicidas ${ }^{111}$. A este respecto, algunas mujeres están convencidas de la divina bondad del suicidio como mártires de la yihad violenta, mientras que otras son «secuestradas, sometidas a presiones psicológicas para convertirlas en asesinas» ${ }^{112}$. La utilización de mujeres permite planificar y llevar a cabo atentados que generen menos sospechas y dedicar el mayor número posible de hombres a los conflictos armados ${ }^{113}$.

Cuando no son víctimas de prácticas como el asesinato o el feticidio, las mujeres se ven obligadas a casarse y a obedecer a sus maridos. Éstos últimos, que en el caso de las mujeres europeas suelen ser contactados por Internet antes del traslado, supervisan a sus esposas y sólo ellos pueden consentir, haciéndolo lícito, el ejercicio de todas sus tareas y todos sus comportamientos (incluso con respecto a las necesidades más básicas de la vida cotidiana) ${ }^{114}$.

Como se ha señalado más arriba, una de las funciones de las mujeres integradas en la organización terrorista es la formación de patrullas dedicadas a moralizar, estigmatizar y castigar cualquier actitud considerada impura. Las mujeres solteras o que aún no han cumplido sus deberes conyugales son segregadas en casas especiales (makkar). Encontrar un marido es el único título para extinguir esta forma de arresto domiciliario y asegurarse el apoyo material necesario para sobrevivir ${ }^{115}$.

Sólo a partir de la fase del conflicto en que el Estado Islámico comenzó a ceder a la presión militar de las fuerzas aliadas se permitió a las mujeres la tenencia de armas en un intento desesperado de evitar la rendición. Por una parte, ello suponía una contradicción, por razones puramente utilitaristas, con el controvertido dogma según el cual las mujeres no deben involucrarse en la violencia yihadista ${ }^{116}$. De otro lado, el Estado Islámico ha dado publicidad oportunista a este cambio presentándolo como un punto de inflexión generacional y como una vía para fomentar la emancipación y la importancia del género femenino ${ }^{117}$.

110 M. CRIEZIS, Online Deceptions: Renegotiating Gender Boundaries on ISIS Telegram, cit., pp. 67 ss.

111 A. KvaKhadze, Women from the Caucasus in the Syrian Conflict, cit., p. 74 (sobre el tema, también, S. DE LeEDE, Women in Jihad: A Historical Perspective, en The International Centre for Counter-Terrorism - The Hague, 2018, https:/icct.nl/wp-content/uploads/2018/09/ ICCT-deLeede-Women-in-Jihad-Sept2018.pdf).

112 G. Olimpio, Terrorismi. Atlante mondiale del terrore, cit., p. 21.

113 Ibidem.

114 R. CRUPI, Al di là del diritto penale: exit strategy dalla radicalizzazione, cit., p. 280, nt. 24; A. KvaKhaDZE, Women from the Caucasus in the Syrian Conflict, cit., pp. 69 ss.

115 Ibidem; A. SPECKHARD, M. ElLENBERG, ISIS and the Militant Jihad on Instagram, cit.

116 N. LaHoud, The Neglected Sex: The jihadis' exclusion of women from Jihad, en Terrorism and Political Violence, 26, 5, 2014, pp. 780 ss.; D. Соок, Women Fighting in Jihad?, en Studies in Conflict and Terrorism, 28, 2005, pp. 275 ss.

117 M. CRIEZIS, Online Deceptions: Renegotiating Gender Boundaries on ISIS Telegram, cit., pp. 67 ss. 
Los menores

La conversión de los menores al fundamentalismo se ve favorecida por sus específicas condiciones personales. Suelen estar influenciados por otros individuos internos y/o externos a sus familias, que se aprovechan de circunstancias como la inmadurez de los menores y su incapacidad para expresar plenamente aspectos centrales de su personalidad ${ }^{118}$; sus dificultades ambientales y relacionales, a menudo exacerbadas por un entorno social incapaz de integrarlos adecuadamente en el respeto mutuo de la diversidad cultural; o, en los casos más dramáticos, la condición de abandono en que se encuentran ${ }^{119}$. Particularmente en estos últimos casos, la identidad frágil o en crisis del menor es explotada por las técnicas terroristas de persuasión antisistema, que ven su eficacia facilitada gracias al aislamiento y/o hostilidad presentes «especialmente en aquellos adolescentes que, partiendo de una fobia social y escolar, abandonan toda relación y contacto social para encerrarse en su habitación, reduciendo al mínimo las relaciones con personas reales, a menudo sustituidas por una actividad frenética en Internet» ${ }^{120}$. Sin embargo, la misma fragilidad o crisis también puede dar lugar, de manera autónoma, a una progresiva radicalización espontánea del menor ${ }^{121}$.

En el proceso de radicalización del menor - en particular, en el segmento que conduce a su reclutamiento paramilitar - interviene también un factor de carácter económico. Especialmente fuera del panorama europeo, a menudo se ofrecen y pagan sumas de dinero a cambio del enrolamiento de menores en las filas del Estado Islámico. Se han recogido testimonios en este sentido en la zona de Oriente Medio, donde la pobreza es una condición dramáticamente extendida ${ }^{122}$.

Algunos combatientes extranjeros desertores también han testificado que, en el Estado Islámico, los niños a partir de los seis años de edad son objeto de abusos físicos y manipulación psicológica, y quedan expuestos a un entorno caracterizado "por ataques suicidas, masacres de disidentes musulmanes, violencias sistemáticas contra las mujeres musulmanas y yazides como esclavas sexuales y la perversión completa del Islam» ${ }^{123}$.

118 G.M. NANNA, Minori, radicalizzazione e terrorismo, Bari, 2018, p. 7.

119 Ivi, pp. 31 ss.

120 G. OlIVA, L.S. GABRIELI, R. GABRIELI, Fondamentalismo e radicalizzazione in immigrati di seconda e terza generazione in Italia e in Europa. Inquadramento psicopatologico e studio dei casi, en Rivista di criminologia, vittimologia e sicurezza, XII, 2, 2018, p. 40.

121 G.M. NANNA, Minori, radicalizzazione e terrorismo, cit., pp. 53 ss.

122 A. SPeckhard, M. Ellenberg, ISIS and the Militant Jihad on Instagram, cit.; en términos generales, L. Risicato, Diritto alla sicurezza o sicurezza dei diritti: un ossimoro invincibile?, Torino, 2019, p. 61.

123 A. Speckhard, A.S. Yayla, A. ShaJkovci, Defeating ISIS on the Battle Ground as well as in the Online Battle Space: Considerations of the "New Normal» and Available Online Weapons in the Struggle Ahead, en Journal of Strategic Security, Vol. 9, núm. 4, 2016, p. 4. También, R. De Bont, D. Weggemans, R. Peters, E. Bakker, Life at ISIS: The Roles of 
Un número cada vez mayor de grabaciones de vídeo y otros materiales reproducen episodios de violencia sufridos - pero a veces incluso perpetrados - por niños. Además, separando y adaptando la educación en función del sexo, las escuelas del Estado Islámico forman a los niños en la ideología fundamentalista a partir de los seis años. Las lecciones de disciplinas ordinarias van acompañadas de estudios históricos y teológicos manipulados, así como por enseñanzas sobre la guerra y sus estrategias.

Los niños son representados por los medios de comunicación terroristas como "víctimas de la intervención occidental contra el Estado Islámico para generar sentimentalismo y frustración en el público» ${ }^{124}$. Esta representación oculta la explotación de los mismos niños como bienes materiales en posesión de los soldados del Estado Islámico para ser aprovechados en apoyo de la causa fundamentalista ${ }^{125}$; y incluso, según el testimonio de un ex combatiente extranjero, ejecuciones sumarias en público como castigo intimidatorio ejemplar por transgresiones consideradas imperdonables (como la blasfemia por nombrar incorrectamente a Mahoma) ${ }^{126}$. Las niñas son catequizadas prematuramente sobre su futuro papel de esposas y madres sumisas.

\section{El incierto destino de las «familias del Estado Islámico»}

Las mujeres, los adolescentes y los niños entran así en el círculo del terror y en su proyección mediática ${ }^{127}$, viéndose profundamente condicionados por un régimen que los aliena y los proyecta en un entorno violento y totalitario. En la actual fase de reorganización del orden territorial del Estado Islámico ${ }^{128}$, algunas mujeres y algunos menores rompieron espontáneamente los lazos con el régimen al rendirse a las fuerzas aliadas, quedando así sometidos al riesgo de futuras represalias por parte de la vasta constelación de grupos terroristas diseminados por el territorio. Otra parte de estos sujetos, capturada durante las misiones de liberación armada, sufre un destino mucho peor. Detenidos en cárceles o

Western Men, Women and Children, en Security and Global Affairs, Special Issue «Jihadists in Syria and Iraq: Recalibrating Concepts, Threat Radar, and Reintegration Policies», cit., pp. 14 ss.

124 A. CHRISTIEN, The Representation of Youth in the Islamic State's Propaganda Magazine Dabiq, cit., p. 5.

${ }_{125}$ Ivi, pp. 5 ss.

126 A. Migotto, S. Miretti, Non aspettarmi vivo. La banalità dell'orrore nelle voci dei ragazzi jihadisti, cit., pp. 25-26.

127 A. BASTENIER, Lo spirito del terrorismo, cit., p. 10.

128 A. Ricci, Geografia, globalizzazione e potere del terrorismo jihadista. L'autorappresentazione globale del califfato, cit., pp. 41 ss.; R. ZEIDEL, H. AL-HASHIMIS, A Phoenix Rising from the Ashes? Daesh after its Territorial Losses in Iraq and Syria, en Perspectives on Terrorism, 13, 3, 2019, pp. 32 ss. 
centros de acogida del calibre de al Hol (en el noreste de Siria, donde la presencia de peligrosas seguidoras del Estado Islámico es todavía considerable), sometidos a torturas y a procesos judiciales no respetuosos de los derechos fundamentales, los menores y sobre todo las mujeres caen en el olvido ${ }^{129}$. A veces son detenidos por Estados, que sistemáticamente se niegan a ejecutar las solicitudes de extradición (salvo en supuestos de corrupción en que los funcionarios públicos aceptan dinero de familiares o grupos militantes para ejecutar la entrega). Otras veces, en los casos de combatientes extranjeros de origen o procedencia europea, la situación de las mujeres y los menores queda paralizada debido al hecho de que los gobiernos siguen siendo recalcitrantes a la hora de planificar su regreso y de encargarse de los riesgos conexos para la seguridad y la estabilidad política del ejecutivo ${ }^{130}$. Además, muchas mujeres han sido asesinadas durante el debilitamiento militar del Estado Islámico para intimidar a las comunidades subyugadas ${ }^{131}$. Otras, junto con sus niños, arriesgan sus vidas en los ataques de las milicias terroristas a las prisiones (entre ellos, el que se lanzó en Jalalabad el domingo 2 de agosto de 2020).

En los casos en que el proceso de radicalización se desarrolla dentro de una familia, las mujeres que se niegan a seguir los pasos extremistas de su marido se enfrentan a veces a una grave presión, desde la imposición del velo completo hasta la violencia doméstica y la infibulación ${ }^{132}$.

\section{Perspectivas y obstáculos en la lucha contra la propaganda y el reclutamiento de terroristas}

Los fenómenos de la propaganda online y del reclutamiento terrorista afectan intensamente al proceso de radicalización al fundamentalismo ${ }^{133}$.

129 «La tasa de retorno de las mujeres sigue siendo significativamente inferior a la de los hombres y los niños [...] Es esencial que las mujeres no se conviertan en el colectivo olvidado»: Naciones Unidas - Consejo de Seguridad, Undécimo informe del Secretario General sobre la amenaza que plantea el EIIL (Daesh) para la paz y la seguridad internacionales y la gama de actividades que realizan las Naciones Unidas en apoyo de los Estados Miembros para combatir la amenaza, cit., p. 10.

130 M. BRESSAN, L'evoluzione della minaccia terroristica alla luce dell'uccisione di alBaghdadi, en \#ReaCT2020 - Rapporto sul terrorismo e il radicalismo in Europa, 2020, pp. 17 ss. De hecho, en Noruega y en Finlandia el debate sobre el posible regreso preferencial de las mujeres y los niños ha llegado incluso a minar al ejecutivo: J. GUY, J. FrATER, S. DEAN, Norway's governing coalition collapses over ISIS repatriation, en CNN, 20 enero 2020, https://edition.cnn.com/2020/01/20/europe/norway-government-collapse-isis-intl/ index.html.

131 S. Dambruoso, Jihad. La risposta italiana al terrorismo: le sanzioni e le inchieste giudiziarie. Con storie di foreign fighters in Italia, cit., p. 87.

132 Ivi, p. 34.

133 Consejo de Seguridad de Naciones Unidas, Décimo informe del Secretario General sobre la amenaza que plantea el EIIL (Dáesh) para la paz y la seguridad internacionales y 
Éste último está determinado o al menos favorecido por elementos de naturaleza heterogénea - sólo en parte religiosos, y a menudo principalmente ideológicos, políticos, sociales, culturales e incluso económicos pero unívocos como causantes de vulnerabilidad. Tales factores pueden o no combinarse, según diferentes componentes psicológicos y existenciales $^{134}$. La vulnerabilidad es la clave en que se apoyan los reclutadores del Estado Islámico, cuya red - organizada en forma paraestatal dentro de sus fortalezas restantes y descentralizada en un número indefinido de células - elabora slogans insidiosamente atractivos y eficaces dentro de un mercado de reclutamiento que sigue expandiéndose.

Sin embargo, las dinámicas de la radicalización, del adoctrinamiento y del reclutamiento de terroristas cambian diacrónicamente y sincrónicamente. La trayectoria hacia el terrorismo está influida por múltiples variables etiológicas que, además de ostentar un grado de relevancia variable en función de cada contexto geográfico, social, cultural, económico, etc., se combinan de diferentes maneras y con diferentes intensidades para cada persona (también dentro del mismo contexto de referencia).

El grado de consolidación de estos fenómenos impide contrarrestarlos con éxito a través de medidas superficiales que no abordan sus condicionantes (geo)políticos, sociales y económicos ${ }^{135}$. Es en cambio necesario investigar las concauses de la adhesión al fundamentalismo y de la progresión hacia el terrorismo para perfeccionar y aplicar estrategias multidisciplinares de prevención extrapenal y desradicalización ${ }^{136}$

la gama de actividades que realizan las Naciones Unidas en apoyo de los Estados Miembros para combatir la amenaza, S/2020/95, 4 febrero 2020, pp. 6-7.

134 L.S. MARTUCCI, Radicalizzati jihadisti: profilazione e deradicalizzazione Constitutioncompliant, cit., p. 9.

${ }_{135}$ Como se ha indicado más arriba, en el plano de las contramedidas adoptadas para hacer frente a la difusión de la propaganda fundamentalista online, los países occidentales están tratando de imponer un mayor control de la red a través de programas de vigilancia e intervención (en forma de eliminación de materiales cargados o cierre de cuentas) en plataformas donde se puede compartir materiales terroristas. Este frente de la lucha contra la propaganda terrorista se encuentra en una fase de perfeccionamiento, pero sigue encontrando diversos obstáculos en la fase de aplicación. Factores como la menor visibilidad y disponibilidad económica de los medios explotados en comparación con gigantes como Google, YouTube, Twitter y Facebook reducirían concretamente la capacidad de los respectivos proveedores para frenar la difusión de material terrorista en línea: A. Shehabat, T. Mitew, Black-boxing the Black Flag: Anonymous Sharing Platforms and ISIS Content Distribution Tactics, cit., p. 97. Además, especialmente en el último decenio, la explotación de la red en las formas y para los fines analizados en este artículo - y en general las prácticas preparatorias, o a veces doblemente preparatorias y de reclutamiento - han sido objeto de un tratamiento penal integral tanto a nivel legislativo como jurisprudencial: F. Rossi, La penalizzazione della propaganda jihadista online in Francia, en Diritto penale contemporaneo, núm. 5, 2019, pp. 125 ss.

136 G. Travaini, E. Regondi, S. Camisasca, P. Caruso, I. Merzagora, I meccanismi di radicalizzazione: giudici e criminologi a confronto, cit., p. 298; M. RomANELLI, Brevi note sulla prevenzione della radicalizzazione jihadista, cit., p. 7; C. SulmonI, Radicalizzazione 
tanto dentro como fuera de prisión ${ }^{137}$. Las instituciones deben compartir activamente con la sociedad civil el objetivo de perfeccionar y aplicar estrategias que sean lo más versátiles posible, en función de la persona implicada y de su historia.

En este contexto, es necesario prestar especial atención a las mujeres y los menores (que, como hemos visto, son los grupos más vulnerables en este ámbito) y asignar más recursos a la especialización de los operadores del sector ${ }^{138}$. Las cuestiones planteadas en este estudio se entrecruzan con la delicada cuestión del tratamiento de las mujeres por parte de los hombres. En síntesis, dentro de las variadas facetas del islam, las versiones más conservadoras imponen a las mujeres una serie de obligaciones, prohibiciones y, en algunos casos, castigos corporales - incluyendo la mutilación genital - que han suscitado una fuerte controversia en Europa. Por un lado, sigue sin resolverse el debate relativo

e de-radicalizzazione. Piste d'indagine, en \#ReaCT2020 - Rapporto sul terrorismo e il radicalismo in Europa, 2020, pp. 20 ss. Según una parte de la doctrina, sería oportuno invertir recursos para desarrollar y difundir una estrategia eficaz contra la propaganda terrorista online, capaz, a su vez, de explotar las modernas técnicas de marketing para sensibilizar a las comunidades en las que el Estado Islámico logra imponerse: ex multis, C. Lister, Profiling the Islamic State, Brookings Doha Center Analysis Paper, Washington, núm. 13, noviembre 2014, p. 39; R. CRUPI, Al di là del diritto penale: exit strategy dalla radicalizzazione, cit., pp. 277 ss.; M. Allam, Jihad in Italia. Viaggio nell'Islam radicale, Milano, 2002, p. 77; H.J. INGRAM, Learning from ISIS's virtual propaganda war for Western Muslims: A comparison of Inspire and Dabiq, en ICCT - The Hague, 26 julio 2017, en particular pp. 9 ss.; Naciones Unidas - Consejo de Seguridad, Décimo informe del Secretario General sobre la amenaza que plantea el EIIL (Dáesh) para la paz y la seguridad internacionales y la gama de actividades que realizan las Naciones Unidas en apoyo de los Estados Miembros para combatir la amenaza, cit., pp. 18-19.

137 Ex multis, C. DEl Prado Higuera, E. SÁnchez de Rojas Díaz, Terrorismo islamista: El caso de Al Gama'a al Islamiyya, cit., pp. 181 ss.; E. Pezzuto, R. Pezzuto, La radicalizzazione nelle carceri, en Comprendere il terrorismo: Spunti interpretativi di analisi e metodologie di contrasto del fenomeno, cit., pp. 61 ss.; S. DAmBRuoso, Jihad. La risposta italiana al terrorismo: le sanzioni e le inchieste giudiziarie. Con storie di foreign fighters in Italia, cit., pp. 177-178; L.S. MARTUCCI, Radicalizzati jihadisti: profilazione e deradicalizzazione Constitution-compliant, cit., en particular p. 22.

138 En cuanto a los niños «vinculados o presuntamente vinculados con grupos armados no estatales, incluso los que cometen actos de terrorismo», el Consejo de Seguridad de Naciones Unidas «Destaca la necesidad de [...] procedimientos operativos estándar para que esos niños sean entregados rápidamente a los agentes civiles de protección infantil que corresponda» (Resolución 2427 (2018), § 19); «Alienta a los Estados Miembros a que presten particular atención a oportunidades de reintegración y rehabilitación sostenibles a largo plazo para los niños afectados por los conflictos armados en las que se tenga en cuenta el género y la edad, incluido el acceso a asistencia sanitaria, apoyo psicosocial y programas educativos, así como a una labor de concienciación y de trabajo con las comunidades para evitar la estigmatización de esos niños y facilitar su regreso, teniendo al mismo tiempo en cuenta las necesidades específicas de niñas y niños, a fin de contribuir a su bienestar y a la paz y la seguridad sostenibles» (ivi, § 26); «Destaca la importancia de una financiación sostenible a largo plazo para programas psicosociales y de salud mental en contextos humanitarios y de velar por que todos los niños afectados reciban apoyo oportuno y suficiente» (ivi, § 27). 
a la línea divisoria entre la determinación autónoma, religiosa y cultural de las mujeres musulmanas y la discriminación o incluso violencia contra ellas. Por otro lado, factores como la percepción de inseguridad, el grado aún muy reducido de conocimiento acerca de los fundamentos del Islam y la compleja integración entre diferentes culturas conducen a la superposición acrítica - y, por lo tanto, a la confusión - entre conservadores «puros», fanáticos extremistas y terroristas. De esta manera se crea una zona gris que dificulta combatir el fenómeno de manera eficaz y al mismo tiempo respetuosa con las exigencias en juego.

Otra cuestión central que los estados europeos están llamados a afrontar es la de los potenciales returnees. Se trata de sujetos con perfiles heterogéneos: «combatientes, no combatientes, mujeres llegadas con sus maridos o [...] para casarse con un combatiente yihadista, niños traídos con sus padres o nacidos en zonas controladas por los terroristas en Siria e Iraq ${ }^{139}$. En todos estos casos (en los que las fiscalías disponen de pocas pruebas que apoyen una acusación sólida), se afirma «el temor de que los prisioneros del ISIS que puedan ser repatriados actúen como potenciales vectores de violencia y adoctrinamiento ideológico para otros, tanto si están detenidos como si se les permite vivir libremente en sus comunidades» ${ }^{140}$.

Por esta razón, el debate sobre la línea de acción penal y/o extrapenal, así como sobre los diversos modelos de vigilancia y rehabilitación de los returnees se encuentra aún por resolver ${ }^{141}$. En las circunstancias actuales, el tratamiento de este problema abocaría a los Estados europeos a afrontar un nuevo aumento de la demanda de vigilancia preventiva y a confiar en programas especializados que se encuentran aún en proceso de desarrollo fragmentario ${ }^{142}$, así como a destinar recursos adecuados a la reintegración de los repatriados en la sociedad.

El tratamiento de estas cuestiones exige la aplicación coordinada de conocimientos especializados para diseñar y ejecutar, de forma adecuada al caso concreto, programas de prevención y disociación del extremismo violento ${ }^{143}$. Tales programas deberán conciliar las mejores prácticas desarrolladas en este ámbito con las necesidades fundamentales de indivi-

139 H. VAN MIERT, The Right Target in Sight? Returnees and the Current Jihadist Threat, cit., p. 37.

140 A. SpeckHard, M. Ellenberg, ISIS and the Militant Jihad on Instagram, cit.

141 Con referencia a Dinamarca, M. Touzari Greenwood, When Foreign Fighters Come Home: The Story of Six Danish Returnees, en Perspectives on Terrorism, 13, 4, 2019, pp. 27 ss., con ulteriores referencias.

142 D. Koenler, V. Fiebig, Knowing What to Do: Academic and Practitioner Understanding of How to Counter Violent Radicalization, en Perspectives on Terrorism, 13, 3, 2019, pp. 44 ss.

143 Ex multis, J. JoRdan, Politicas de prevención de radicalización violenta en Europa: elementos de interés para España, en Revista Electrónica de Ciencia Penal y Criminología, 11-05, 2009, http://criminet.ugr.es/recpc/11/recpc11-05.pdf. 
dualización científica del tratamiento, así como con el derecho inviolable a la autodeterminación.

Así mismo, el correcto planteamiento de estos fenómenos requiere también una profundización de los estudios empíricos sobre su desarrollo y evolución. Desde esta perspectiva resulta de particular interés, por ejemplo, además del ya mencionado aspecto de las repercusiones futuras de la pandemia de Covid-19, el historial de disociación y/o «desradicalización espontánea» de sujetos desilusionados por su experiencia en el Estado Islámico ${ }^{144}$. La coordinación de los programas de prevención y desradicalización antes mencionados con estudios empíricos realizados en un contexto político, interreligioso y socio-cultural más amplio (y libre de las distorsiones populistas) ${ }^{145}$ ayudaría a cohesionar a las comunidades en riesgo, su apoyo es necesario para combatir más eficazmente la radicalización y el terrorismo: por tanto, la colaboración con las autoridades como socios iguales ${ }^{146}$ en un paradigma más sensible al diálogo y la reintegración en la sociedad debe ser estimulada ${ }^{147}$. Francia y Reino Unido (pero también, por ejemplo, los Países Bajos) han adoptado los primeros pasos en esta dirección. En 2014, Francia aprobó un programa de lucha contra la radicalización basado en la movilización de «la sociedad en su totalidad (asociaciones de barrios, mezquitas) - y los servicios del Estado en contacto con un amplio público (educación nacional, servicios sociales, sanidad, cárceles)», así como de las prefecturas y otras instituciones, «para garantizar el diálogo con las autoridades locales representativas de los musulmanes» ${ }^{148}$. El Reino Unido, por su parte, ha adoptado el programa «CONTEST» («The United Kingdom's

144 P.R. Neumann, Victims, Perpetrators, Assets: The Narratives of Islamic States Defectors, en ICSR, 2015, https://icsr.info/wp-content/uploads/2015/10/ICSR-ReportVictims-Perpetrators-Assets-The-Narratives-of-Islamic-State-Defectors.pdf; A. SPECKHARD, M. ELLENBERG, ISIS and the Militant Jihad on Instagram, cit.

145 M. PAPA, Il fiqh al-aqalliyyāt e il proselitismo islamico, en Quaderni di diritto e politica ecclesiastica, 1, 2020, en particular p. 175.

146 F. RAGAZZI, Policed multiculturalism? The impact of counter-terrorism and counterradicalization and the 'end' of multiculturalism, en C. Baker-Beall, C. Heath-Kelly, L. Jarvis (cur.), Counter-Radicalisation. Critical Perspectives, London-New York, 2014, p. 158. Esta cooperación también puede relanzarse útilmente en términos de "premios» en materia penal: D. CASTRONuovo, Quale lezione dagli «anni di piombo»? La legislazione dell'emergenza e sui pentiti in prospettiva storica e comparata, en Diritto penale XXI secolo, 1, 2019, pp. 143 ss.; F. Diamant, Misure premiali e terrorismi. Dall'esperienza italiana all'ultima evoluzione del terrorismo islamista, en Legislazione Penale, 5 diciembre 2019.

147 S. WITTENDORP, Displacing the National Security-Narrative: on the (de-) securitization of the Governmental and Legal response to 'Foreign Fighters', en Security and Global Affairs, Special Issue "Jihadists in Syria and Iraq: Recalibrating Concepts, Threat Radar, and Reintegration Policies», cit., p. 23. Ofrecen un análisis comparado L. VIDINO, J. BRANDON, Countering radicalization in Europe, London, 2012, passim. Los estándares internacionales se encuentran recogidos en la Resolución 2482/2019 del Consejo de Seguridad de Naciones Unidas, § 17-18 y 20.

148 Gouvernement Valls III, Plan d'action contre la radicalisation et le terrorisme, Dossier de Presse, 9 mai 2016 («PART»): F. RAgazzI, S. DAvidshofER, S. PERrET, A. TAWFiK, 
Strategy for Countering Terrorism»), parte del cual («PREVENT») ${ }^{149}$ está dedicada a promover un «enfoque coordinado [...] que aúna al Gobierno, al sector público en general y a los individuos en torno al objetivo común de prevenir el terrorismo» ${ }^{150}$. Merece también una mención el programa «Channel», un plan de intervenciones educativas, laborales y de asistencia psicológica para prestar apoyo a las personas vulnerables a la radicalización. Sin embargo, a pesar de la vivacidad de los debates a nivel nacional y supranacional y de la existencia, en algunos casos, de proyectos de ley, otros países (Italia, por ejemplo) se están quedando atrás.

Sin embargo, en la esfera de la prevención del terrorismo, el desequilibrio entre los enfoques duros y blandos sigue siendo excesivamente pronunciado. Como resultado, los incentivos para cooperar con las autoridades son mitigados. Además, la importancia de la corresponsabilidad social y geopolítica en la génesis del terrorismo todavía no se ha abierto paso en el debate político y mediático ${ }^{151}$, y el universo islámico "es considerado en gran parte por la opinión pública europea como la 'religión de los extranjeros', una especie de cuerpo extraño a los valores de la civilización continental» ${ }^{152}$ que aún carece de una conciencia cosmopolita madura $^{153}$. La demonización de la realidad islámica, la marcada (y a veces superficial) desconfianza hacia la posible reversibilidad del proceso de radicalización y las reacciones de una minoría de los musulmanes agudizan sentimientos de odio y dificultan paliar la división entre «nosotros» $\mathrm{y}$ «ellos» ${ }^{154}$.

Les effets de la lutte contre le terrorisme et la radicalisation sur les populations musulmanes en France. Enquête quantitative, París, 2018, p. 3.

149 «The United Kingdom's Strategy for Countering Terrorism», pp. 31 ss.

150 Ivi, p. 3. D. Lowe, Terrorism: Law and Policy, London-New York, 2018.

151 R. Coolsaet, T. StRuYe De Swielande, Epilogue: Zeitgiest and (De-)Radicalisation, en R. Coolsaet (cur.), Jihadi Terrorism and the Radicalization Challenge in Europe: European and American experiences, Aldershot, 2008, p. 159.

152 R. Guolo, L'ultima utopia. Gli jihadisti europei, cit., p. 20.

153 Z. BAuman, Communitas. Uguali e diversi nella società liquida, cur. por C. Bordoni, Reggio Emilia, 2013.

154 El fenómeno ha sido descrito como la coexistencia de «sociedades paralelas» por M.A. CANO PAÑos, Las sociedades paralelas en Europa en el contexto de la inmigración y su eventual influencia en la radicalización islamista de sus miembros, en J. Bernal del Castillo (cur.), L. Roca de Agapito, M.M. González Tascón (coord.), Delito y minorías en países multiculturales. Estudios jurídicos y criminológicos comparados, Barcelona, 2014, pp. 207 ss.; N. Sanz Mulas, Las sociedades paralelas como cantera del yihadismo, en El terrorismo en la actualidad: un nuevo enfoque político criminal, cit., pp. 247 ss. 


\section{Bibliografía}

ACAMPA S., "Applicazione delle tecniche di content analysis ai magazine di propaganda dello stato islamico: la chiamata alle armi di Rumiyah», Rivista di Criminologia, Vittimologia e Sicurezza, Vol. XII, Núm. 2, 2018.

Albanese D., «Le motivazioni della Corte d'Assise di Milano sul «caso Fatima»: spunti di riflessione su terrorismo internazionale e organizzazione di trasferimenti ex art. 270-quater.1 c.p.», Diritto penale contemporaneo, 28 marzo 2017, https://archiviodpc.dirittopenaleuomo.org/d/5302-le-motivazioni-della-corte-dassise-di-milano-sul-casofatima-spunti-di-riflessione-su-terrorismo-in.

Allam M., Jihad in Italia. Viaggio nell'Islam radicale, Milano, 2002.

Atwan A.B., Islamic State: The Digital Caliphate, Berkeley, 2015.

Awan I., "Cyber-Extremism: Isis and the Power of Social Media», Society, Vol. 54, Iss. 2, 2017.

Baker-Beall C., Heath-Kelly C., Jarvis L. (cur.), Counter-Radicalisation. Critical Perspectives, London-New York, 2014.

BARBERIS M., Non c'è sicurezza senza libertà. Il fallimento delle politiche antiterrorismo, Bologna, 2017.

BAstenier A., Lo spirito del terrorismo, trad. por L. Tirocchi, Roma, 2019.

BaUman Z., Communitas. Uguali e diversi nella società liquida, cur. por C. Bordoni, Reggio Emilia, 2013.

Bauman Z., Paura liquida, Bari, 2010.

BERMEJo R., «¿Qué tienen en común las respuestas a la COVID-19 y al extremismo violento?», The Conversation, 2 julio 2020, https://theconversation.com/que-tienen-en-comun-las-respuestas-a-la-covid-19-y-alextremismo-violento-141056.

Bernal del Castillo J. (cur.), Roca de Agapito L., González Tascón M.M. (coord.), Delito y minorías en países multiculturales. Estudios jurídicos y criminológicos comparados, Barcelona, 2014.

Bernardini M.G., Disabilità, giustizia, diritto. Itinerari tra filosofia del diritto e Disability Studies, Torino, 2016.

Bernardini M.G., Casalini B., Giolo O., Re L. (cur.), Vulnerabilità: etica, politica, diritto, Roma, 2018.

Beutel A., Weine S.M., Saeed A., Spahic Mihajlovic A., Stone A., Oakley Beahrs J., Shanfield S.B, «Field Principles for Countering and Displacing Extremist Narratives», Journal of Terrorism Research, Vol. 7, Iss. 3, 2016. 
BRESSAN M., "L'evoluzione della minaccia terroristica alla luce dell'uccisione di al-Baghdadi», \#ReaCT2020 - Rapporto sul terrorismo e il radicalismo in Europa, 2020.

BuRIL F., "Changing God's Expectations and Women's Consequent Behaviors - How ISIS Manipulates «Divine Commandments» to Influence Women's Role in Jihad», Contemporary Voices, Vol. 8, Iss. 3, 2017.

CAHN O., "Quel accueil pour les djihadistes de retour en France ? Les mesures et les qualifications envisageables», Revue pénitentiaire et de droit penal, Núm. 1, 2018.

Cano Paños M.A., «Odio e incitación a la violencia en el contexto del terrorismo islamista. Internet como elemento ambiental», Revista para el Análisis del Derecho, Núm. 4, 2016, http://www.indret.com/ pdf/1248.pdf.

Cano Paños M.A., Castro Toledo F.J., «Un análisis de las fases del proceso de radicalización islamista y su interpretación por parte de los tribunales españoles a partir de los datos suministrados por sentencias judiciales», Revista Electrónica de Ciencia Penal y Criminología, núm. 20-15, 2018.

Christien A., «The Representation of Youth in the Islamic State's Propaganda Magazine Dabiq», Journal of Terrorism Research, Vol. 7, Iss. 3, 2016.

CIAPPINA V., "Videogiochi e cyber jihad: dimensioni ed effetti», \#ReaCT2020 - Rapporto sul terrorismo e il radicalismo in Europa, 2020.

Cook D., «Women Fighting in Jihad?», Studies in Conflict and Terrorism, 28, 2005.

COOLSAET R. (cur.), Jihadi Terrorism and the Radicalization Challenge in Europe: European and American experiences, Aldershot, 2008.

CRIEZIS M., "Online Deceptions: Renegotiating Gender Boundaries on ISIS Telegram», Perspectives on Terrorism, 14, 1, 2020.

CRIscuolo G., «L'evoluzione della comunicazione dello stato islamico», \#ReaCT2020 - Rapporto sul terrorismo e il radicalismo in Europa, 2020.

CUKANI E., «Soggetti vulnerabili e tutela dei diritti: il caso dei minori stranieri non accompagnati», Consulta online, II, 2019.

DAmBRuoso S., Jihad. La risposta italiana al terrorismo: le sanzioni e le inchieste giudiziarie. Con storie di foreign fighters in Italia, Roma, 2018.

Davis J., Women in Modern Terrorism: From Liberation Wars to Global Jihad and the Islamic State, Maryland, 2017.

De Bont R., Weggemans D., Peters R., Bakker E., «Life at ISIS: The Roles of Western Men, Women and Children», Security and Global Affairs, Special Issue "Jihadists in Syria and Iraq: Recalibrating Con- 
cepts, Threat Radar, and Reintegration Policies», septiembre 2017, https://www.universiteitleiden.nl/en/news/2017/09/sga-special-issue.

DE LEEDE S., "Women in Jihad: A Historical Perspective», The International Centre for Counter-Terrorism - The Hague, 2018, https://icct.nl/wpcontent/uploads/2018/09/ICCT-deLeede-Women-in-Jihad-Sept2018. pdf.

De Maglie S., Seminara S. (cur.), Terrorismo internazionale e diritto penale, Padova, 2007.

De Rosa C., Fiorillo A., "Oltre la religione. Il reclutamento dei foreign fighter nello Stato Islamico (ISIS)», Rassegna Italiana di Criminologia, núm. 4, 2017.

del Prado Higuera C., Sánchez de Rojas Díaz E., Terrorismo islamista: El caso de Al Gama'a al Islamiyya, Valencia, 2018.

Diamanti F., «Misure premiali e terrorismi. Dall'esperienza italiana all'ultima evoluzione del terrorismo islamista», Legislazione Penale, 5 diciembre 2019.

Dieu E., Testouri L., Sorel O., «Proposition d'une méthodologie d'évaluation de l'identité en voie de radicalisation", Revue internationale de criminologie et de police technique et scientifique, Vol. LXXII, Núm. 4, 2019.

FASANI F., Terrorismo islamico e diritto penale, Milano, 2016.

GALLI F., The Law on terrorism: The UK, France and Italy compared, Bruselas, 2015.

Garapon A., Rosenfeld M., Démocraties sous stress. Les défis du terrorisme global, París, 2016.

Ghajar-Khosravi S., Kwantes P., Derbentseva N., Huey L., «Quantifying Salient Concepts Discussed in Social Media Content: An Analysis of Tweets Posted by ISIS Fangirls», Journal of Terrorism Research, Vol. 7, Iss. 2, 2016.

Guolo R., L'ultima utopia. Gli jihadisti europei, Milano, 2015.

GuY J., Frater J., DEAN S., «Norway's governing coalition collapses over ISIS repatriation», $C N N, 20$ enero 2020, https://edition.cnn. com/2020/01/20/europe/norway-government-collapse-isis-intl/index. html.

INGRAM H.J., «Learning from ISIS's virtual propaganda war for Western Muslims: A comparison of Inspire and Dabiq», ICCT - The Hague, 26 julio 2017.

JACOBSEN S.J., "Calling on Women: Female-Specific Motivation Narratives in Danish Online Jihad Propaganda», Perspectives on Terrorism, 13, 4, 2019. 
JoINSON A.N., «Self-disclosure in computer-mediated communication: the role of self-awareness and visual anonymity», European Journal of Social Psychology, Núm. 31, 2000.

JORDAN J., «Políticas de prevención de radicalización violenta en Europa: elementos de interés para España», Revista Electrónica de Ciencia Penal y Criminología, 11-05, 2009, http://criminet.ugr.es/recpc/11/ recpc11-05.pdf.

Khosrokhavar F., I nuovi martiri di Allah, Torino, 2003.

Kimmel P.R., Stout C.E. (cur.), Collateral Damage: The Psychological Consequences of America's War on Terrorism, Westport, 2006.

Koenler D., Fiebig V., «Knowing What to Do: Academic and Practitioner Understanding of How to Counter Violent Radicalization», Perspectives on Terrorism, 13, 3, 2019.

Kvakhadze A., «Women from the Caucasus in the Syrian Conflict», Perspectives on Terrorism, 14, 2, 2020.

LaHoud N., «The Neglected Sex: The jihadis' exclusion of women from Jihad», Terrorism and Political Violence, 26, 5, 2014.

LAMBERTI C., "Gli strumenti di contrasto al terrorismo e al cyber-terrorismo nel contesto europeo», Rivista di Criminologia, Vittimologia e Sicurezza, Vol. VIII, Núm. 2, 2014.

LEGRENZI P., «Reazioni al terrorismo. Vulnerabilità, paura, rischio e pericolo», il Mulino, Núm. 6, 2001.

Lister C., «Profiling the Islamic State», Brookings Doha Center Analysis Paper, Washington, n. 13, noviembre 2014.

Lowe D., Terrorism: Law and Policy, London-New York, 2018.

LuCAS S., "Syria Interview: Islamic State of Iraq's Abu Sumayyah alBritani on Conflict and the Caliphate», EA Worldview, 11 junio 2004, https://eaworldview.com/2014/06/syria-interview-islamic-state-of-iraqabu-sumayyah-al-britani-conflict-caliphate/.

MARTUCCI L.S., «Laicità e diritti nei programmi di deradicalizzazione dal terrorismo religioso», Dirittifondamentali.it, núm. 4, 2018.

MARTUCCI L.S., «Radicalizzati jihadisti: profilazione e deradicalizzazione Constitution-compliant», Dirittifondamentali.it, núm. 8, 2019.

MCKENNA K.Y.A., BARGH J.A., "Coming out in the age of the internet: identity "demarginalization» through virtual group participation", Journal of Personality and Social Psychology, Vol. 75, Iss. 3, 1998.

Meleagrou-Hitchens A., Hughes S., «The Threat to the United States from the Islamic State's Virtual Entrepreneurs», CTC Sentinel10, Núm. 3, 2017, https://ctc.usma.edu/the-threat-to-the-united-statesfrom-the-islamic-states-virtual-entrepreneurs/. 
Migotto A., Miretti S., Non aspettarmi vivo. La banalità dell'orrore nelle voci dei ragazzi jihadisti, Torino, 2017.

Militello V., Spena A. (cur.), Mobilità, sicurezza e nuove frontiere tecnologiche, Torino, 2018.

Milton D., Dodwell B., «Jihadi Brides? Examining a Female Guesthouse Registry from the Islamic State's Caliphate», CTC Sentinel, 11, 5, 2018.

Mollica A., «Firenze, sospetti terroristi nel centro minori», Corriere della sera, 11 maggio 2018, https://corrierefiorentino.corriere.it/firenze/notizie/cronaca/18_maggio_11/firenze-sospetti-terroristi-centro-minori9cc2ebac-54e7-11e8-998a-93ce1f846824.shtml.

MorÁn Blanco S., "La ciberseguridad y el uso de las Tecnologias de la Información y la Comunicación (TIC) por el terrorismo», Revista española de derecho internacional, Núm. 2, 2017.

Moyano M., Trujlllo H., Radicalización islamista y terrorismo. Claves psicosociales, Granada, 2013.

Mullins S., 'Home-Grown' Jihad. Understanding Islamist Terrorism in the US and UK, London, 2016.

Mwenda KaILEmia W., "The Spectacle of Terrorism: Exploring the Impact of 'Blind Acting Out' and 'Phatic Communication'», Journal of Terrorism Research, Vol. 7, Iss. 2, 2016.

NANNA G.M., Minori, radicalizzazione e terrorismo, Bari, 2018.

NARDI V., «La punibilità dell'istigazione nel contrasto al terrorismo internazionale. Il difficile bilanciamento tra esigenze di sicurezza e libertà di espressione», Diritto penale contemporaneo - Rivista trimestrale, Núm. 1, 2017.

Nesser P., Stenersen A., «The Modus Operandi of Jihadi Terrorists in Europe», Perspectives on Terrorism, Vol. 8, Iss. 6, diciembre 2014.

Neumann P.R., «Victims, Perpetrators, Assets: The Narratives of Islamic States Defectors», ICSR, 2015, https://icsr.info/wp-content/ uploads/2015/10/ICSR-Report-Victims-Perpetrators-Assets-The-Narratives-of-Islamic-State-Defectors.pdf.

Olimpio G., Terrorismi. Atlante mondiale del terrore, Milano, 2018.

OlIVA G., GABRIELI L.S., GABRIELI R., «Fondamentalismo e radicalizzazione in immigrati di seconda e terza generazione in Italia e in Europa. Inquadramento psicopatologico e studio dei casi», Rivista di criminologia, vittimologia e sicurezza, XII, 2, 2018.

Pantucci R., «Key Questions for Counter-Terrorism Post COVID-19», RSIS, https://raffaellopantucci.com/2020/04/24/key-questions-forcounter-terrorism-post-covid-19/, 24 abril 2020. 
PAPA M., "Il fiqh al-aqalliyyªt e il proselitismo islamico», Quaderni di diritto e politica ecclesiastica, Núm. 1, 2020.

PerCeVAl J.M., El terror y el terrorismo. Cómo ha gestionado la humanidad sus miedos, Madrid, 2017.

PÉrez CEPEDA A.I. (dir.), M. Ruiz Arias (coord.), El terrorismo en la actualidad: un nuevo enfoque político criminal, Valencia, 2018.

Pezzuto R., «Contenuti terroristici on line: l’Unione europea lavora a nuove norme per prevenirne la diffusione», Diritto penale contemporaneo, 5 abril 2019, https://www.penalecontemporaneo.it/d/6603contenuti-terroristici-on-line-l-unione-europea-lavora-a-nuovenorme-per-prevenirne-la-diffusione.

Ragazzi F., Davidshofer S., Perret S., TAwFiK A., Les effets de la lutte contre le terrorisme et la radicalisation sur les populations musulmanes en France. Enquête quantitative, París, 2018.

RANSTORP M. (cur.), Understanding violent radicalization: terrorist and jihadist movements in Europe, London-New York, 2009.

RAZZANTE R. (cur.), Comprendere il terrorismo. Spunti interpretativi di analisi e metodologie di contrasto del fenomeno, Pisa, 2019.

Risicato L., Diritto alla sicurezza o sicurezza dei diritti: un ossimoro invincibile?, Torino, 2019.

Romanelli M., "Brevi note sulla prevenzione della radicalizzazione jihadista», Sistema Penale, 20 marzo 2020.

Rossi F., «La penalizzazione della propaganda jihadista online in Francia», Diritto penale contemporaneo, núm. 5, 2019.

Rossi F., «The Multifactorial Process of Radicalisation to «Jihadi» Fundamentalism», Criminal Justice Network, 28 junio 2020.

SANZ Mulas N., Las sociedades paralelas como cantera del yihadismo, en M. RUIZ ARIAs (coord.), El terrorismo en la actualidad: un nuevo enfoque político criminal, Valencia, 2018.

SERAFINI M., L'ombra del nemico. Una storia del terrorismo islamista, Milano, 2020.

SERAFINI M., "Trieste, il jihadista di 15 anni e il team di pedagogisti che prova a rieducarlo», Corriere della sera, 7 abril 2018, https://www. google.it/amp/www.corriere.it/esteri/18_aprile_07/minorenne-facevapropaganda-isis-telegram-sara-deradicalizzato-0eb0369a-3a24-11e8a94c-7c30e3109c4d_amp.html.

Shehabat A., Mitew T., «Black-boxing the Black Flag: Anonymous Sharing Platforms and ISIS Content Distribution Tactics», Perspectives on Terrorism, Vol. 12, Iss. 1, 2018. 
Shehabat A., Mitew T., Alzoubi Y., "Encrypted Jihad: Investigating the Role of Telegram App in Lone Wolf Attacks in the West», Journal of Strategic Security, Vol. 10, Núm. 3, 2017.

Silke A. (cur.), Prisons, Terrorism and Extremism: Critical Issues in Management, Radicalisation and Reform, London-New York, 2014.

Speckhard A., Ellenberg M., "ISIS and the Militant Jihad on Instagram», Homeland Security Today, https://www.hstoday.us/subjectmatter-areas/cybersecurity/isis-and-the-militant-jihad-on-instagram/, 21 julio 2020.

Speckhard A., Ellenberg M., "Jesse Morton: A Story of Trauma and Radicalization», Homeland Security Today, 25 agosto 2020, https:// www.hstoday.us/subject-matter-areas/counterterrorism/jesse-mortona-story-of-trauma-and-radicalization/.

Speckhard A., Yayla A.S., ShaJkovci A., "Defeating ISIS on the Battle Ground as well as in the Online Battle Space: Considerations of the "New Normal» and Available Online Weapons in the Struggle Ahead», Journal of Strategic Security, Vol. 9, Núm. 4, 2016.

Sulmoni C., "Radicalizzazione e de-radicalizzazione. Piste d'indagine», \#ReaCT2020 - Rapporto sul terrorismo e il radicalismo in Europa, 2020.

Teruel Lozano G.M., "Internet, incitación al terrorismo y libertad de expresión en el marco europeo», InDret, Núm. 3, 2018.

Touzari Greenwood M., «When Foreign Fighters Come Home: The Story of Six Danish Returnees», Perspectives on Terrorism, 13, 4, 2019.

Travaini G., Regondi E., Camisasca S., Caruso P., Merzagora I., «I meccanismi di radicalizzazione: giudici e criminologi a confronto», Rassegna Italiana di Criminologia, núm. 4, 2017.

TsFati Y., WeIMANN G., "www.terrorism.com: Terror on the Internet», Studies in Conflict and Terrorism, Vol. 25, Iss. 5, 2002.

VAN DER HEIDE L., GEENEN J., "Children of the Calipate: Young IS Returnees and the Reintegration Challenge», Security and Global Affairs, Special Issue "Jihadists in Syria and Iraq: Recalibrating Concepts, Threat Radar, and Reintegration Policies», septiembre 2017, https:// www.universiteitleiden.nl/en/news/2017/09/sga-special-issue.

VIDINO L., Il jihadismo autoctono in Italia: nascita, sviluppo e dinamiche di radicalizzazione, Milano, 2014.

VIDINO L., BRANDON J., Countering radicalization in Europe, London, 2012.

WENIN R., Fornasari G. (cur.), Diritto penale e modernità. Le nuove sfide fra terrorismo, sviluppo tecnologico e garanzie fondamentali, Napoli, 2017. 
WiTTENDORP S., «Displacing the National Security-Narrative: on the (de-) securitization of the Governmental and Legal response to 'Foreign Fighters'», Security and Global Affairs, Special Issue "Jihadists in Syria and Iraq: Recalibrating Concepts, Threat Radar, and Reintegration Policies», septiembre 2017, https://www.universiteitleiden.nl/en/ news/2017/09/sga-special-issue.

YAR M., JeweKes Y. (cur.), Handbook of Internet Crime, Milton, 2010.

Zeidel R., AL-Hashimis H., "A Phoenix Rising from the Ashes? Daesh after its Territorial Losses in Iraq and Syria», Perspectives on Terrorism, 13, 3, 2019. 
